Article

\title{
Prediction of Socio-Economic Indicators for Urban Planning Using VHR Satellite Imagery and Spatial Analysis
}

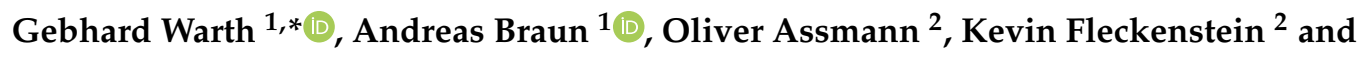 \\ Volker Hochschild ${ }^{1}$ \\ 1 Institute of Geography, University of Tübingen, Ruemelinstrasse 19-23, 72070 Tübingen, Germany; \\ an.braun@uni-tuebingen.de (A.B.); volker.hochschild@uni-tuebingen.de (V.H.) \\ 2 AT-Association, Waldburgstrasse 96, 70563 Stuttgart, Germany; oliver.assmann@at-verband.de (O.A.); \\ k.fleckenstein@stud.uni-heidelberg.de (K.F.) \\ * Correspondence: gebhard.warth@uni-tuebingen.de
}

Received: 22 April 2020; Accepted: 25 May 2020; Published: 28 May 2020

\begin{abstract}
Ongoing urbanization leads to steady growth of urban areas. In the case of highly dynamic change of municipalities, due to the rates of change, responsible administrations often are challenged or struggle with capturing present states of urban sites or accurately planning future urban development. An interest for urban planning lies on socio-economic conditions, as consumption and production of disposable goods are related to economic possibilities. Therefore, we developed an approach to generate relevant parameters for infrastructure planning by means of remote sensing and spatial analysis. In this study, the single building defines the spatial unit for the parameters. In the case city Belmopan (Belize), based on WorldView-1 data we manually define a city covering building dataset. Residential buildings are classified to eight building types which are locally adapted to Belmopan. A random forest (RF) classifier is trained with locally collected training data. Through household interviews focusing on household assets, income and educational level, a socio-economic point (SEP) scaling is defined, which correlates very well with the defined building typology. In order to assign socio-economic parameters to the single building, five socio-economic classes (SEC) are established based on SEP statistics for the building types. The RF building type classification resulted in high accuracies. Focusing on the three categories to describe residential socio-economic states allowed high correlations between the defined building and socio-economic points. Based on the SEP we projected a citywide residential socio-economic building classification to support supply and disposal infrastructure planning.
\end{abstract}

Keywords: VHR imagery; WorldView-1; PlanetScope; urban remote sensing; socio-economic information; urban planning indicators; Belmopan/Belize; spatial analysis

\section{Introduction}

During the present century urbanization will be one of the major challenges for society, politicians, and planners. Urbanization as a complex socio-economic process that transforms the built environment, converting formerly rural into urban settlements [1], has-besides all well-known challenging tasks-positive effects for society, such as economic growth, poverty reduction, and human development of urbanization [2]. "Urban areas also serve as hubs for development, where the proximity of commerce, government and transportation provide the infrastructure necessary for sharing knowledge and information. Urban dwellers are often younger, more literate and more highly educated, are more likely to have access to decent work, adequate housing and social services, and can 
enjoy enhanced opportunities for cultural and political participation as well as gender equality" [2]. When urbanization progresses unguided, effects of inadequate planning are evident: unsustainable production and consumption patterns and impaired sustainability resulting from urban sprawl, pollution, and environmental degradation [1].

A basic challenge is the lack of capacity within public institutions to manage urbanization [1]. To guide and direct urbanization in order to achieve its potential positive effects and to enable implementing the sustainable development goals (SDG) proclaimed by the United Nations [3], paradigms for urban planning, therefore, need to be shifted towards transparent approaches of evidence-based planning [4]. Infrastructure planning should be considered as a core element in strategic spatial planning, based on the understanding of the underlying forces, which includes knowledge of the economic base amongst other things [5].

Socio-economic parameters can serve as indicators for both urban supply and disposal infrastructure planning. Knowledge of education and economic situations have importance relevant to household waste production in various regions [6-8], more precisely household income and household expenditures correlate accurately with household solid waste generation [9]. Jones (2015) shows in a review article [10] the influence of socio-economic criteria on the consumption of electricity with the household income as the main factor.

We see a growing potential regarding the use of remote sensing techniques to supply socio-economic information for planning urban supply and disposal infrastructure-a potential which has not been considered in present research as the following paragraphs show.

To characterize urbanization, first global datasets of urban expansion were established based on Landsat data [11] and optical nighttime imagery data [12]. The global urban footprint dataset was fully generated automatically based on TanDEM-X synthetic aperture radar (SAR) data [13,14]. Most recently, the world settlement footprint for the years 2012 and 2015 were generated by combining Sentinel-1 radar data and optical Landsat- 8 data [15]. To increase the spatial resolution of the information and to retrieve qualitative information on the change that occurred between different acquisitions, Warth et al. proposed a method to retrieve information on dynamics in building stock on a single building scale by differencing urban digital surface models (DSM) [16]. Braun et al. [17] refined these results publishing a refined urban change dataset on single building scale for Da Nang, VN.

With the increasing availability of VHR remote sensing imagery, there is a need for techniques to detect objects as a spatial and radiometric product of multiple pixels. Object based image analysis (OBIA) techniques [18] have been used to detect single buildings [19,20]. Recent studies show the implementation of OBIA techniques for measuring urban ecosystem functionality [21,22] and indication of quality of life factors $[23,24]$. Foci on approaches for image-based object detection approaches have been shifted most recently towards machine learning (ML) methods [25]. The approaches were successfully implemented using VHR remote sensing imagery [25,26]. Regarding context based VHR image analysis in the urban context, a focus lies on mapping slums and informal settlements using ML techniques [27-29]. Zhu [30] gives an overview on the key developments regarding ML approaches in urban remote sensing. As a recent example, morphological descriptions of neighborhoods retrieved by VHR images and spatial distance measures have been successfully applied to predict property values in other cases [31].

Three-dimensional data derived by photogrammetric approaches [32] supports the physical description of building stock analysis and detecting changes in building stock [16,33]. Light Detection and Ranging (LiDAR) approaches using the propagation of light [34] in the urban context have advantages in vegetation related studies and therefore are applied for tree species detection [35], urban forest mapping [36], volume estimation [37], and urban ecosystem service (ESs) modelling [38].

Besides the application of SAR data for generating global settlement data and mapping of impervious surfaces [39], radar technology the ability to detect changes in elevation offered by processing of the phase information [40]. The increased availability of Sentinel-1 time series data [41] enables implementing Persistent Scatterer Interferometry (PSI) to precisely monitor surface deformation 
processes [42]. Besides analyzing subsidence as an effect of ground water extraction [43-45], subsidence could be correlated to construction projects [46-48] by PSI technique. SAR tomography approaches [49] are performed in the urban context with Sentinel-1 [50,51] and TanDEM-X data [52]. Interferometric SAR products have been proven to enable the detection of urban flood extension [53].

To support urban planning on a city level, information related to function and context is required. In this regard, Kuffer worked on the mapping of slum areas [54,55], ML based approaches have been performed as well [27-29]. Socio-economic parameters as planning relevant indicators have been derived by Jensen [56], where population and quality-of-life-indices were estimated by means of VHR imagery. Approaches using Landsat-5 TM data were described by Lo [57]. Urban vegetation is an indicator for socio-economic rating [58]. In this context, urban mapping and planning can benefit from ESs mapping that helps indicating urban quality factors and urban climate $[59,60]$.

Socio-economic data gathering and analyzing methods that use socio-economic indices to determine the relative socio-economic status of individuals or households in a sample group have been applied with different purposes in various scientific fields. Important areas of research include medical and epidemiological studies [61,62], educational studies [63], or the measuring of inequality in living standards [64] or health [65]. The research focus in these studies lies in the evaluation of the correlation between the socio-economic status and health conditions [66-68]. With the help of criteria like educational level, occupation, and income the influence of the socio-economic status on health and life expectancy of an individual is examined [69].

The goals of urban planning must be to guide and to manage the dynamics of municipalities which are caused by many factors, such as persistent urbanization amongst other things. Successfully implemented urban planning enables citizens to obtain benefit from the advantages of urbanization, like "access to education, health care and housing, to increase their productivity and to expand opportunity" [70] and enables the realization of the SDGs [3]. Therefore, decision makers need to adopt strategies towards planning future urban growth [70]. Knowledge on present states and dynamics of the urban complex is decisive to plan the future development of a city and its surroundings. In the case of rapidly growing urban agglomerations, it is challenging to capture current dynamics because of the rate of change and the inertia of many data gathering methods.

With this study we follow up previous work of designing a development plan for green and blue infrastructure for Belmopan [71]. Belmopan is a small capital city with 23,038 inhabitants [72] and can be used as a practical example considering, as Cohen and Barney predict, a majority of urban dwellers will be living in small cities $(<100,000$ inhabitants) [2]. Special focus needs to be applied on such cities, because these municipalities often lack basic services such as piped water, flush toilets, and electricity [2]. In Latin America and Caribbean region, where the study area of this research is located, waste production is expected to increase by one third by 2050 as compared to 2016 and $58 \%$ of waste ends up in landfills and open dump sites [73], which causes negative environmental effects.

To establish methods of evidence-based planning and therefore to reduce the gap of data and knowledge, we propose an approach to support planning of residential supply and disposal infrastructure by predicting socio-economic information at the scale of residential buildings using very high-resolution (VHR) remote sensing imagery. VHR optical remote sensing systems, such as the WorldView or Pléiades satellites, deliver imagery at sub-meter resolution, which allows the precise detection of buildings with high temporal flexibility. The access to VHR imagery is improved and the constant data availability is being established [74,75]. A lot of research has been carried out to describe and prove the relationships between consumption of energy and waste production via socio-economic indicators. The influence of the socio-economic status (SES) on the urban metabolism-in terms of material and energy flows generated by households-at the level of individual buildings has not yet been researched in this way. As a new scientific issue, the correlation of different socio-economic states-along with potentially differing consumption and generation patterns-to varying building types is researched within this study. The purpose being to derive relevant values for a well-founded planning of supply and disposal infrastructure. In the context of planning appropriate supply and 
disposal infrastructure in dynamic environments this correlation might be very important and should be considered with respect to the building of a reliable database.

To put these findings in effect when planning, remote sensing data sources should be implemented to support planning processes, in addition to reasons of objectivity and time efficiency, qualitative and quantitative information relevant for planning can be gathered region-wide.

\section{Materials and Methods}

\subsection{Study Area and Data}

\subsubsection{Study Area}

While still a British Colony known as British Honduras, the study city of Belmopan was inaugurated in 1970 as the new capital city [76]. The maps in Figure 1 give an overview on Belmopan's location. Due to its geographical location, the former capital Belize City was repeatedly threatened by hurricanes, the last major hurricane named Hattie hit Belize city and the Belize district in 1961 destroying approximately $80 \%$ of the city $[76,77]$.

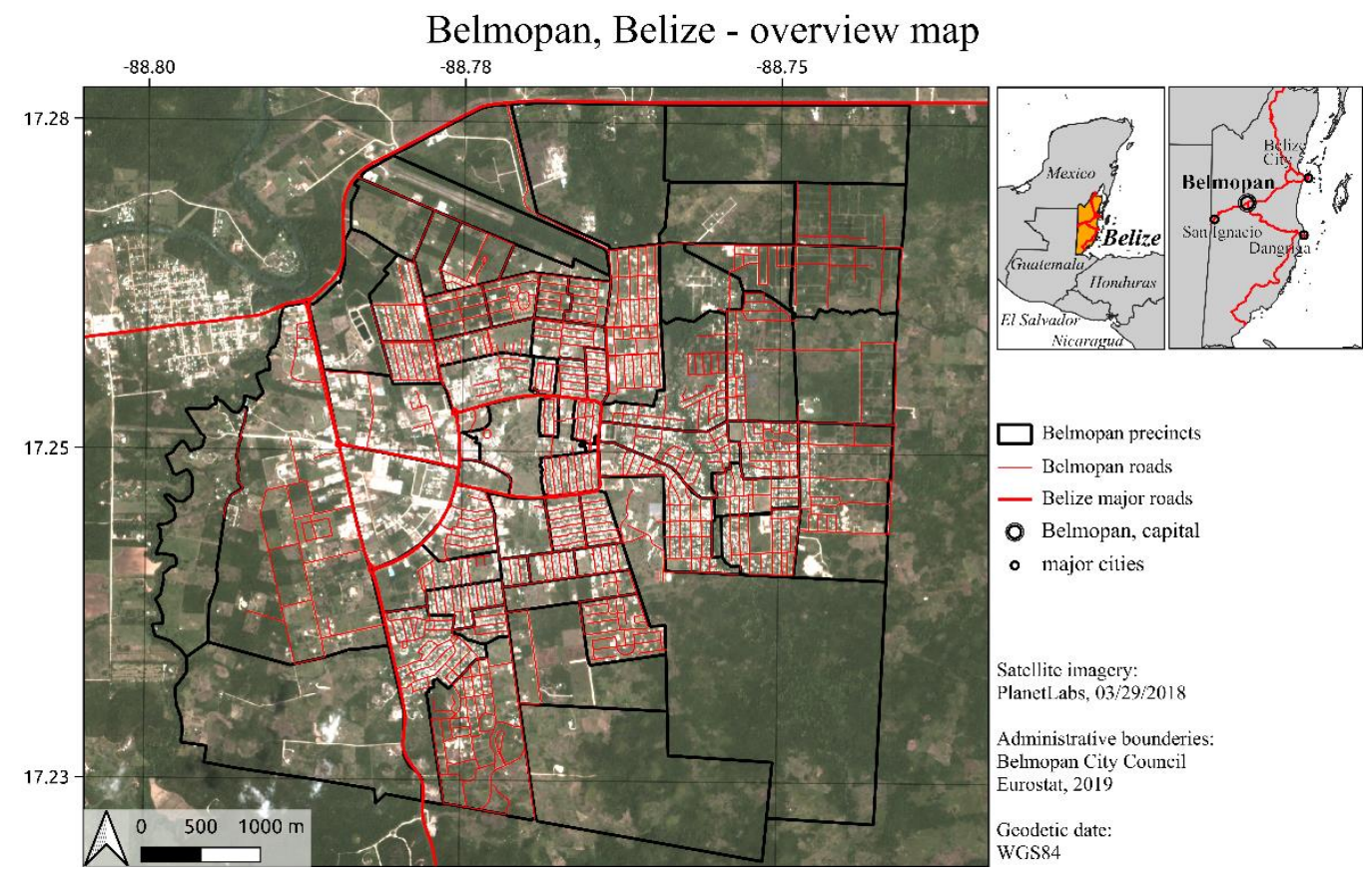

Figure 1. General map of Belmopan and its regional geographical situation.

Besides causing human losses and physical damage, the hurricanes interrupted governmental work and destroyed governmental documents, as well [76]. In addition to reduction of risk of natural hazards, which was the main reason for the relocation of the capital, the dominant and authoritative position of Belize City in the country was reduced by the inauguration of the new capital city of Belmopan [76]. The decision on the location for the new capital was based on the following main criteria: (1) a potable water supply, (2) safety from flooding, (3) its location at the hub of national transportation network and (4) equidistance from the two largest coastal centers of Belize City and Stann Creek [76]. The city name of Belmopan was inspired by the confluence of the Belize river and Mopan river. Administrative data indicate an area of $32.25 \mathrm{~km}^{2}$ covered by the Belmopan administrative boundaries.

In 2018 Belize had a population of 398,050 inhabitants, whereas 23,038 people lived in Belmopan [72]. In comparison to global and regional urbanization rate, Belize is estimated to be experiencing above-average urbanization [1], as it is shown in a global and regional comparison in Figure 2. 
The Belmopan annual population growth rate is estimated at 5.7\% [78]. These dynamics underline the necessity for standardized urban mapping at regular intervals.

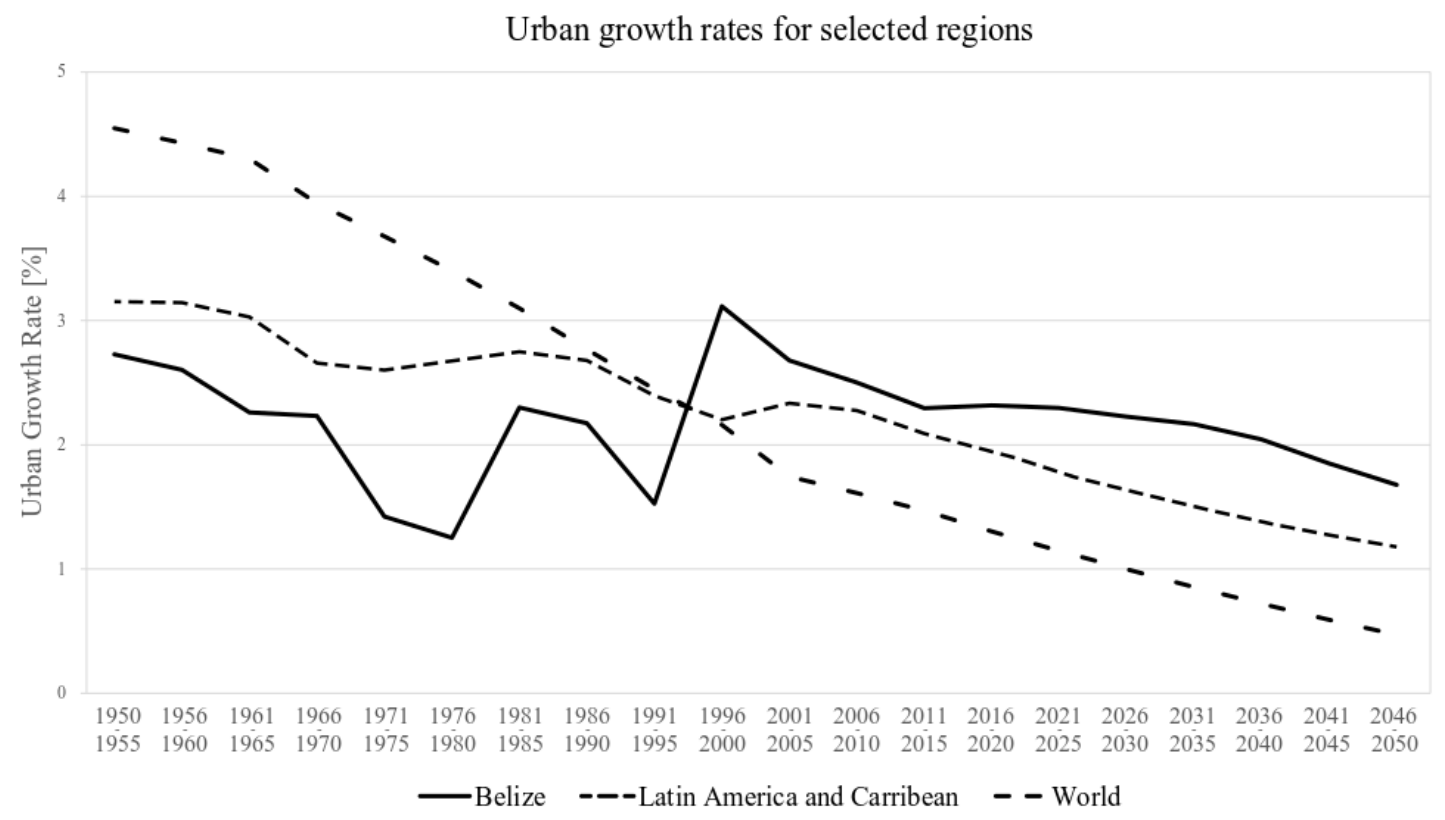

Figure 2. Comparison of measured and prospected urban growth rates for Belize, the Latin America and Caribbean region and the World as based on UN data [1].

\subsubsection{VHR Imagery}

The WorldView-1 (WV-1) satellite, launched in 2007, offers stereo imagery, which is achieved by a single pass bi-directional acquisition mode. At nadir, the panchromatic band has a ground sampling distance of $0.5 \mathrm{~m}$ [79]. In this research two stereo image scenes were used acquired on 2018/03/16 and on 2018/03/29, respectively, as shown in Table 1, in order to achieve high quality results the datasets cover $28.04 \mathrm{~km}^{2}$ of the Belmopan administrative area. A total of $13.1 \%$ of the administrative area not covered by the WV-1 imagery is undeveloped. For the imagery data radial polynomial coefficients (RPC) are delivered by the imagery provider. The first scene has a share of cloud-covered areas of $6.3 \%$, affected areas lie partly above built-up zones. For details on WV-1 imagery and acquisition please refer to Table 1.

Table 1. Overview on WorldView-1 acquisitions used.

\begin{tabular}{cccc}
\hline & $\begin{array}{c}\text { WorldView-1 Stereo } \\
\text { Pair 1 }\end{array}$ & $\begin{array}{c}\text { WorldView-1 Stereo } \\
\text { Pair 2 }\end{array}$ & $\begin{array}{c}\text { PlanetScope } \\
\text { Two Frames }\end{array}$ \\
\hline Acquisition date & $2018 / 03 / 16$ & $2018 / 03 / 29$ & $2018 / 03 / 29$ \\
Ground sampling distance & $0.5 \mathrm{~m}$ & $0.5 \mathrm{~m}$ & $3.0 \mathrm{~m}$ \\
In track view angles & $-24.3^{\circ}, 15.3^{\circ}$ & $-9.4^{\circ}, 29.9^{\circ}$ & $0.1^{\circ}, 0.12^{\circ}$ \\
Cloud coverage & $6.3^{\circ}$ & $0.2^{\circ}$ & $0 \%$ \\
\hline
\end{tabular}

\subsubsection{HR Imagery}

PlanetScope data were chosen to get access to multispectral imagery [80]. Images acquired on 2018/03/29 were selected to achieve minimum cloud coverage and identical image contents in comparison with the WV-1 imagery described in Section 2.1.1. PlanetScope operates in a sun synchronous orbit with a four-band frame imager. The visual spectrum is captured by the blue $(455-515 \mathrm{~nm})$, green $(500-590 \mathrm{~nm})$, and red $(590-670 \mathrm{~nm})$ channels at a ground sampling distance of $3 \mathrm{~m}$. The near infrared spectrum is captured at 780-860 nm [81]. The PlanetScope imagery is delivered radiometrically preprocessed in surface reflectance values. In the imaging mode as used, 
a PlanetScope scene covers $180 \mathrm{~km}^{2}$, but the entire urban area of Belmopan was not covered in a single scene. Therefore, two scenes were used for the analyses. Figure 3 gives an overview on the used satellite imagery.

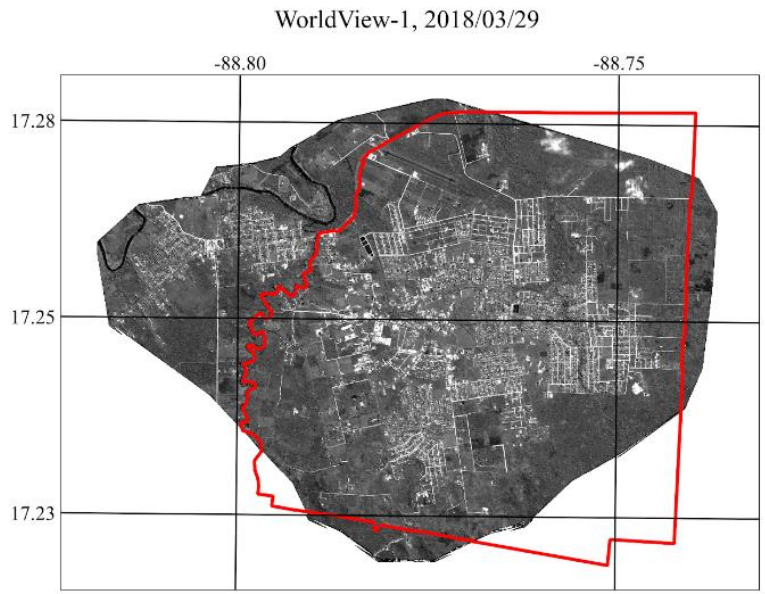

(a)

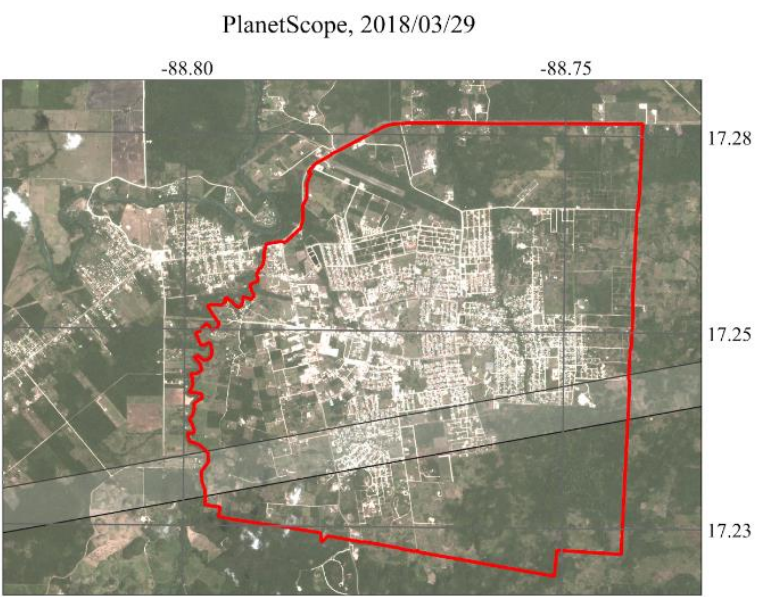

(b)

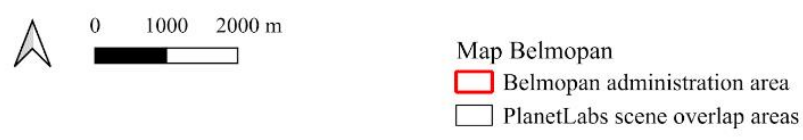

Figure 3. Overview of satellite imagery used for the study. The red polygon shows the Belmopan city boundary. (a) WorldView-1 image covering the developed areas of Belmopan. (b) PlanetScope images fully covering Belmopan.

\subsubsection{Ground Truthing Data}

A questionnaire-based survey using the mobile KoboCollect tool [82] was performed to collect ground truthing data for the building type classification. During two field campaigns in January and March 2019 datasets with a total sample size of 405 building were collected. Each building was assigned to the building types defined in Section 2.2.4. Additionally, information on the number of stories, mean roof height, roof type, and parcel-related information describing accessibility and vegetation share were collected. Building height information was measured with a Bosch GLM 50C handheld laser measurement device. Locations of the buildings surveyed were recorded with handheld GPS devices and manually location corrected-based on the WorldView-1 imagery in a geographical information system (GIS) (see Section 2.1.2.).

\subsubsection{Auxiliary Data}

Auxiliary data on non-residential building use was collected during the field campaigns. Non-residential building use was sub-classified into business, public sector, and industry. The non-residential buildings were collected by GPS measurements as point information and position corrected based on the WorldView-1 image. The collected building-use information was added with information on business, public sector (administration, education, health institutions), and industry based on OpenStreetmap (OSM) [83] and Google registrations. Data on the official plan of land use, administrative boundaries (sectors, precincts, and parcels), as well as on the road network and public transportation infrastructure were provided by the city council of Belmopan as vector geometries.

\subsubsection{Socio-Economic Interviews}

For gathering socio-economic data and information on household level in Belmopan an interview-based survey was designed and carried out in March and April 2019. KoboCollect was used as described in Section 2.1.4. According to the six main representative building types 
determined for Belmopan and their detected shares/spatial concentration in the city (Section 2.2.5), test areas were defined for the implementation of the socio-economic survey. Building types 23 and 24 (see Section 2.2.4) do not occur in statistically sufficient numbers in Belmopan. Within the test areas a total of 425 households were surveyed by means of digital questionnaires with about 210 questions on the main subject areas:

- $\quad$ housing and infrastructure (type and devices of the house);

- $\quad$ specific information on the household (size, age structure, occupation, education, etc.);

- $\quad$ items, features and devices (assets) owned by the household;

- $\quad$ expenditures (on housing, food, health, etc.) of the household;

- food and buying habits of the household;

- income (amount, sources) of the household.

\subsection{Methods}

Our proposed methodology predicts socio-economic measures on a single building scale, Figure 4 schematically shows the single steps of the approach. Basing on VHR remote sensing imagery, single buildings are detected. Supported by local ground truthing information, building types are classified. Through statistical analysis of resident's interviews, a relationship between building types and socio-economic groups can be established. Detailed information on the methodology is given in the following sections.

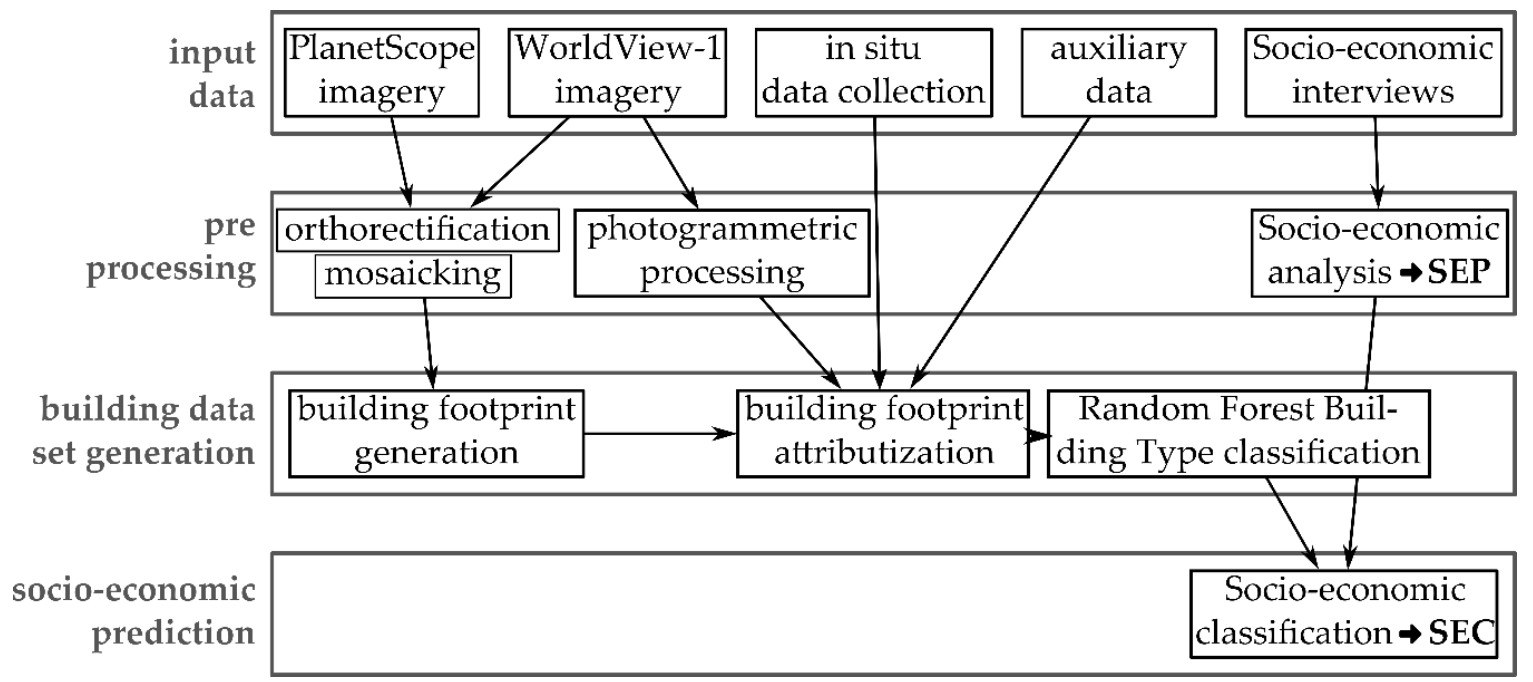

Figure 4. Schematic overview of the approach. Socio-economic analysis leads to the "socio-economic points" (SEP) ranking (see Section 2.2.6. and Section 3.3.). The prediction of socio-economic status bases on building types via socio-economic classes (SEC) (see Section 2.2.7. and Section 3.4.).

\subsubsection{VHR Image Processing}

In order to orthorectify WV-1 imagery for generating the building dataset and to derive building heights, the WV-1 data described in Section 2.1.1, were processed photogrammetrically. To increase the quality in urban areas, two stereo pairs were chosen to achieve a fourfold coverage. The off-nadir angles are clearly differentiated, as shown in Table 1, and therefore the usage of four input images increase the quality of the resulting elevation dataset.

For the photogrammetric processing, the EATE approach in ERDAS Imagine [84] was chosen, as already implemented by Bachofer and Warth [16,33].

The main elevation dataset was calculated with all four WV-1 images. To replace cloud affected pixels, a substitute elevation dataset was calculated based on the cloud free image pair. 
For cloud-covered pixels, elevation information of the main dataset was substituted with elevation data from the alternative elevation dataset. In addition to this, the fourfold coverage reduces the impact of the cloud coverage on small parts.

In order to determine building heights from WV-1 height information, a normalized DSM (nDSM) was calculated. A digital terrain model (DTM) was generated based on the WV-1 DSM. Therefore, building heights were removed by means of building footprints (see Section 2.2.2) and heights affected by tree or forest were removed as well via threshold based NDVI (see Section 2.2.3) masking using PlanetScope imagery. The resulting gaps in the DSM were closed by applying spline interpolation. Differencing DSM and DTM gives the nDSM, which contains height information on buildings, trees, and other non-ground objects.

\subsubsection{Delineation of Building Footprints}

On the base of the orthorectified WV-1 scene from 2019/03/29, the building dataset was generated. With an HPF multi-resolution approach the orthorectified PlanetScope scene was pansharpened using the panchromatic WV-1 scene to combine the very high spatial resolution of the panchromatic channel with the multispectral information delivered in the PlanetScope scene. The orthorectified scene is the correctly positioned main basis for the manually observed building detection. In cases of indistinct building outline, the unrectified WV-1 scene without distortions caused by the orthorectification was used as reference. To digitize building footprints the Java-OpenStreetMap-Editor (JOSM) [85] was used for reasons of simple digitization and attributization routines and the intended publishing of the building dataset on the OpenStreetmap server.

\subsubsection{HR Image Processing}

As two acquisitions are necessary for full coverage of the Belmopan city, both PlanetScope scenes were mosaicked. No preprocessing before the mosaicking was necessary due to the data delivery already being surface reflectance. The orthorectification process for multispectral PlanetScope imagery was performed by an RPC based approach implemented in ERDAS Imagine. Data on RPC for the PlanetScope imagery was delivered by the data provider. The WV-1 DSM, described in Section 2.2.1, was used as very high-resolution elevation data input.

Based on the orthorectified multispectral imagery, the normalized difference vegetation index (NDVI) was calculated to delineate vegetated areas. Studies $[60,86]$ have proven that NDVI based tree detection approaches deliver practicable results in urban environments. Applied to PlanetScope imagery, the NDVI is derived as follows:

$$
\mathrm{NDVI}_{\text {PlanetScope }}=\frac{\text { PlanetScope Band } 4-\text { PlanetScope Band } 3}{\text { PlanetScope Band } 4+\text { PlanetScope Band } 3}
$$

For the generation of the normalized DSM which represents object heights, a tree mask must be calculated to distinguish between trees and ground level areas. Observations during the field campaigns have shown, that grass is very low in Belmopan and therefore can be interpreted as ground elevation in the DSM. To separate between ground and tree covered areas, a histogram-based threshold-based approach was chosen. In the histogram a local minimum value between the NDVI values of tree covered areas and non-tree covered areas represents the threshold to create the tree mask. Based on the PlanetScope scene acquired on 2018/03/29, the NDVI threshold is 0.21.

\subsubsection{Definition of Building Typology}

The prediction of socio-economic status bases on building type information. Therefore, the method aims to propose a global definition for residential building types. This study focusses on the prediction of socio-economic indicators on residential buildings, as other building functions cannot be derived solely based on remote sensing information. In this regard, we defined eight residential building types 
(BT), which are denominated by numbers and neutral designations, in order to avoid preconceptions of its residents and surrounding neighborhoods. Buildings types 11-14 represent single family buildings, whereas building types 21-24 represent multifamily buildings. We define the term "Multi-Family Building" as a building with two or more residential units, as already suggested by Vetter-Gindele et al. [87]. The proposed building types are defined by construction materials used and the physical structure of the buildings and have no significance over the building condition or building maintenance. For building type nominations see Table 2.

Table 2. Building types with respective nomination.

\begin{tabular}{cccc}
\hline Building Type & Nomination & Building Type & Nomination \\
\hline BT 11 & Single Family Basic & BT 21 & Multi-Family \\
BT 12 & Single Family Standard & BT 22 \\
BT 13 & Single Family Advanced & BT 23 & Multi-Family Standard \\
BT 14 & Single Family Complex & BT 24 & Multi-Family Apartment \\
\end{tabular}

Due to cultural and historical influence, building types differ worldwide and therefore must be adapted to local building structures. For Belmopan we assigned the buildings to the building typology as follows.

Buildings with one dwelling unit were assigned from BT 11 to BT 14. The main criteria for the assignment of BT 11 is the use of natural construction materials. BT 12 is characterized by four corners, rectangular building footprint and gabled or shed roof types. BT 13 can be similar to BT 12, but shows deviations from the rectangular footprint. Additional stories can also exist, but not full stories. Buildings with multiple full stories are assigned to BT 14, as well as buildings with complex footprints and complex roof structures.

BT 21 is the only Multi-Family Building type with two dwelling units at a single floor building structure. It is usually characterized by gabled or shed roofs and, therefore, can only be structurally differentiated from BT 12/13 by increased footprint area. In Belmopan, BT 22 is characterized by a simple rectangular footprint. Usually these buildings enclose two dwelling units on two stories. BT 23 contains multiple apartments; the increased footprint area allows multiple apartments per story. The number of stories can exceed two. BT 24 is a modern multifamily apartment, which is constructed by modern materials and highly equipped with modern technical devices. It shows complex footprints and roof structures. Table 3 and Figure 5 give an overview on the building typology for Belmopan.

Table 3. Building typology for Belmopan, criteria to visual on-site differentiation.

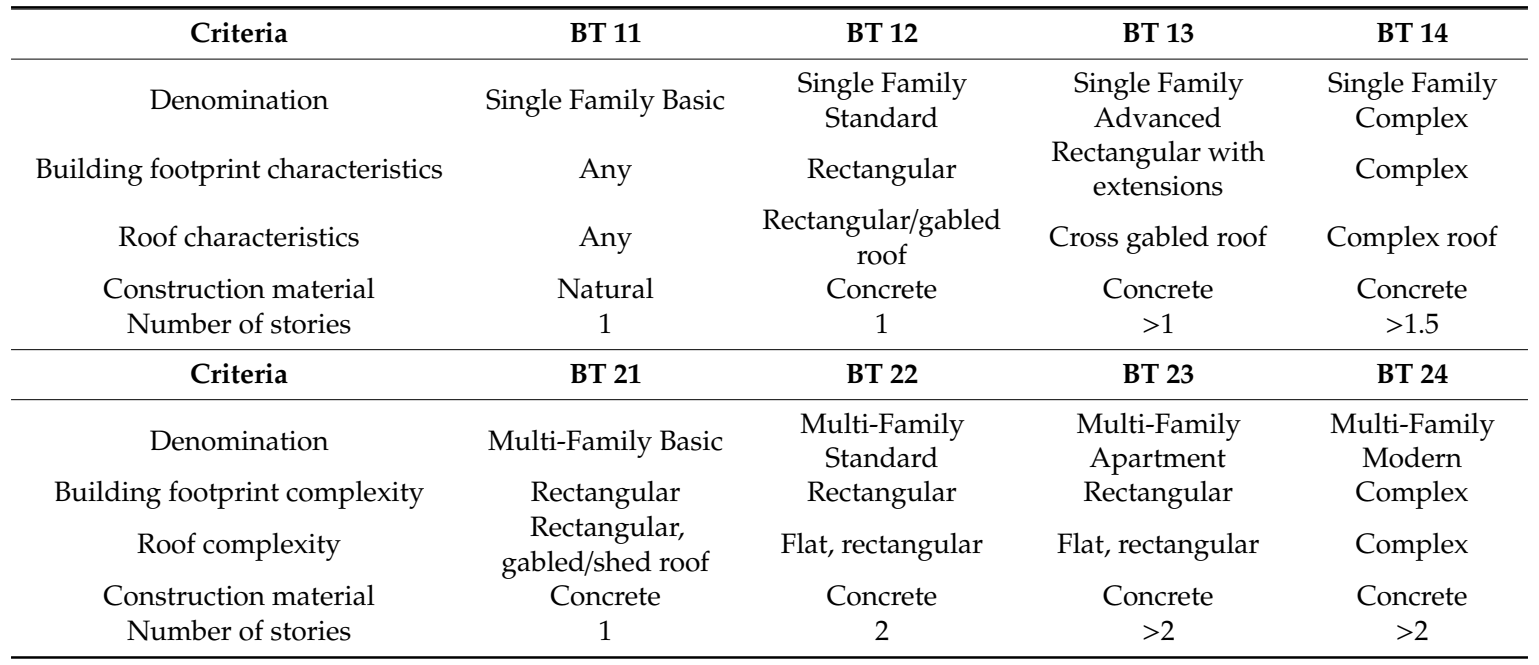




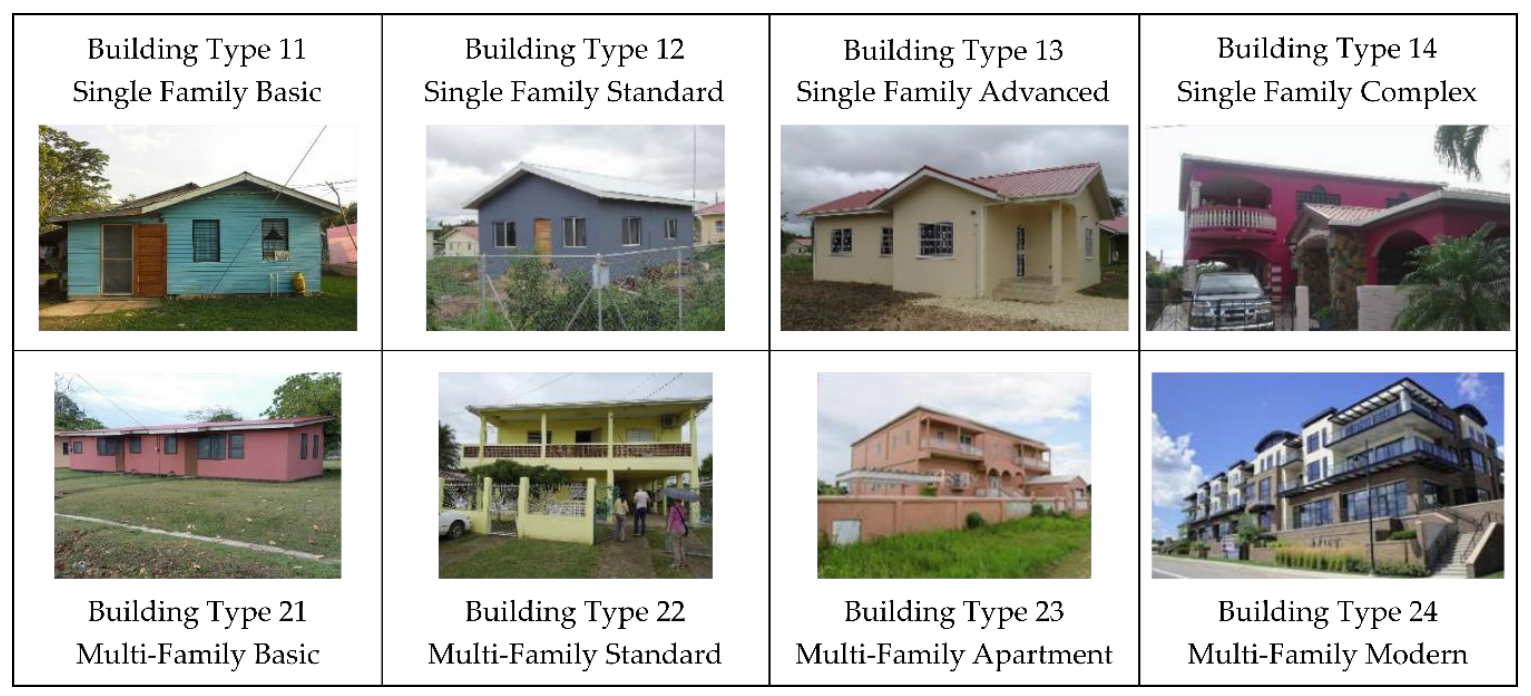

Figure 5. The proposed building typology adapted to the case city Belmopan, Belize. Upper row representing single family buildings, lower representing multi-family buildings. Image sources Building Type 23: [88].

\subsubsection{Classification of Building Types}

The classification of building types was conducted in two steps. First a supervised classification was conducted based on the reference classes collected during the field survey (Section 2.1.4.). Of the 405 collected buildings, 363 were identified as residential and used for the training. A variety of attributes were computed per building polygon that served as explanatory features for the prediction:

- Geometry features $(n=6)$ : area; perimeter; number of corners; shape ratio (area/perimeter); shape index [89]; average height (Section 2.2.1.).

- Distance features (Euclidean, $n=8$ ): roads; paved roads; bus lines; parcels of land use commercial; parcels of land use education; parcels of land use green spaces; parcels of land use industry; parcels of land use public.

- Density features $(n=5)$ : average building density within a radius of 150 and $250 \mathrm{~m}$; absolute number of buildings within 50,100, and $200 \mathrm{~m}$.

- Land use features (according to the official plan provided by the city council, $n=2$ ). 10 parcel classes: agriculture, commercial, education, green space, industrial, mixed use, public/institutional, residential, utilities, vacant. Four sector classes: built-up, developing, vacant/agriculture/forest, university.

- $\quad$ Spectral features (average per polygon, $n=4$ ): HR red; HR green; HR blue; HR infrared.

These 25 features were used for the training of a random forest classifier, an algorithm originating from machine learning, which repeatedly uses subsets of the training data and explanatory features to calculate classification trees based on variable thresholding [90]. In our case, 1500 trees were computed based on five randomly selected features and 236 randomly selected building types for training (subset of $65 \%$ ). In the end, a final classification is retrieved for each building based on the majority class of all 1500 iterations.

This resulted in a classification of all buildings in the city. Of course, buildings which were attributed as public, commercial, industrial, or uninhabited based on the field survey or data from OpenStreetMap and Google Maps were not assigned a residential building type.

\subsubsection{Processing of Socio-Economic Data}

The key assumption underlying our approach of gathering relevant data for supply and disposal infrastructure planning is that different socio-economic groups of households living in different 
building types have different habits and lifestyles, which in turn result in different material and energy flows. In order to prove this correlation, the different socio-economic states of the households in Belmopan had to be determined and classified before assigning them to different building types.

All 425 interviews were checked for plausibility. In the case of unrealistic replies and insufficient numbers of replies for statistical categorization, such related questionnaires were not considered. A total of 395 out of the 425 socio-economic datasets surveyed in Belmopan proved to be statistically reliable after initial analyses. In order to determine the socio-economic status of the surveyed households as relative position in the sample groups, a multidimensional approach was developed. Similar to the "Social Class Index" applied in a German health survey [91], the socio-economic index developed within this current study is based on three categories of questions and their respective answers. On the basis of the socio-economic data gathered in Belmopan the categories which proved to be appropriate for creating the relevant index were:

1. Expenditures.

2. Educational level.

3. Household assets (owned items).

Expenditures was chosen as the first category because answers involving questions on expenditures in an interview-based survey are usually more reliable than those on income [92]. The OECD equivalence square root scale was used to take differences in household sizes and nonlinearities with respect to growing household sizes and related expenditures into account [93]. The educational level was integrated in the index with six different characteristics. Following the "Udai Pareek Scale" developed to examine the socio-economic status of rural population in India by Singh (2017) [92], the third category focusses on the different assets (owned items) of the household. This allows contemplating the financial situation of a household in a long-term perspective.

The six different educational levels ascertained for Belmopan, ranging between "no graduation (category 1)" and "Master/or higher (category 6)", determined the main structure of the six classes in each category of the socio-economic index which was developed via this context. Following this structure, the total expenditures of the households were grouped into six classes of equal size. Likewise, the household assets (owned items) queried with binary questions were divided into six classes to fit into this structure.

In order to determine the socio-economic status of a surveyed household, and so to make it comparable, points were assigned to the six classes in the three primary categories, thus forming a point scheme ranging from 3 to 18 socio-economic points. As a result, a generated proxy variable within this scheme with a value of 3 determines the lowest and with a value of 18 the highest socio-economic status (SES) of a household.

\subsubsection{Classification and Prediction of Socio-Economic Data}

Related to the building types, socio-economic projections can be assigned to the single buildings, as described in the previous section. To avoid the impression of precision of the 15-point scale (3-18), and a source of errors in the prediction of socio-economy, socio-economic points are aggregated into socio-economic classes (SEC). Besides reducing errors in predicting socio-economic information, it can be critical to publish detailed sensitive information regarding resident's socio-economic status at a single building level. Creating classes helps avoid the possibility of instrumentalizing the results so to marginalize and expose residents of single buildings. Therefore, because different building types can host dwellers of similar socio-economic status, there is no reason to define an identical number of SEC as building types. The determining criterion for the number of SEC must be the statistical similarity of SEP.

Furthermore, as land value varies depending on the location and distance from places of urban activity, the necessity to subdivide building types based on spatial and location-based information may be identified. Studies have shown that the highest land values are to be expected in the city 
centers and central business districts $[31,94]$. Without local expertise it is hardly possible to define a city center, to which the land value development is related and to access the key influences on value generation. Therefore, for this purpose, besides interviewing local experts [95] we created a set of quality of life indicators [56,57] by means of geo-spatial attributes to test the process of building types subdivision. The distance US Embassy located in Belmopan hereby was considered as quality of life indicator because the security service regularly patrols the surrounding neighborhood, which leads to higher security and due to this causes higher land values. Our selection results in the following quality of life indicators:

- distance to main roads (ring road)

- distance to administrative center (city administration);

- distance to places of education;

- distance to market center (market square);

- distance to US Embassy;

- building density;

- vegetation density.

Correlating the above geo-spatial attributes to building types with high variation in socio-economical description enables determining a threshold to divide a building type in the subclasses "near" and "far", e.g., building type "12 near" and building type "12 far". The subdivision "near" represents spatial proximity to city center, "far" represents buildings relatively distant to the city center.

\section{Results}

\subsection{Building Detection}

Following the goal to give free access to the building footprints via the OSM database, the already existing buildings had to be adjusted to the 2018/03/29 WV-1 acquisition. The standard base image on OSM was acquired between 2008 and 2010. This could be verified via the water treatment plant being under construction in the base image, which was under construction in the stated period. Therefore approximately 1500 pre-existing buildings were adjusted to their correct location by means of the orthorectified WV-1 scene and their building footprints updated accordingly. Buildings which were generated on the previous scene, which are no longer present in the recent acquisition, were removed for the present state of the database.

Based on this initial building footprint adaption the remaining buildings were digitized. At the time the WV-1 image was acquired on 2019/03/29 we detected a total number of 6627 buildings.

\subsection{Building Type Classification}

The initial trainings accuracy of the random forest classifier was comparably low: $56.7 \%$. This is because there was considerable class overlap between the building types Single Family Basic, Standard, and advanced, as well as between Single Family Standard and Multi-Family Standard as shown in Table 4. Accordingly, user's and producer's accuracies are largely below $60 \%$. To reduce this overlap, the created building type classifications were refined through logical expressions based on the criteria presented in Table 3 and statistical evaluation of critical thresholds. For instance, any building which was classified as Single Family (BT1x) but has a size below $30 \mathrm{~m}^{2}$ will be reclassified to "uninhabited". Hereby to reclassify building types, the building height is an important building attribute. A set of 249 building measurements was measured in situ to verify the building heights derived by the WV- $1 \mathrm{nDSM}$. The accuracy analysis revealed a root mean square error (RSME) of 1.23 (measurement unit: meters), which indicates good quality of the determined building heights. A chart containing information in this respect is shown in Appendix A. The full list of the applied rules is shown in Appendix B. 
Table 4. Error matrix of building types after the random forest classification.

\begin{tabular}{cccccccccccc}
\hline & & \multicolumn{1}{c}{ Classified } & & & & PA \\
\hline & & BT11 & BT12 & BT13 & BT14 & BT21 & BT22 & BT23 & BT24 & \\
& BT11 & $\mathbf{1 8}$ & 20 & 1 & 0 & 0 & 0 & 0 & 0 & 39 & 46.2 \\
& BT12 & 4 & 105 & 21 & 0 & 2 & 1 & 0 & 0 & 133 & 78.9 \\
& BT13 & 0 & 33 & 48 & 3 & 1 & 1 & 1 & 0 & 87 & 55.2 \\
real & BT14 & 1 & 2 & 15 & 18 & 2 & 3 & 2 & 0 & 43 & 41.9 \\
& BT21 & 1 & 6 & 6 & 2 & 4 & 1 & 0 & 0 & 20 & 20.0 \\
& BT22 & 0 & 9 & 3 & 7 & 0 & 5 & 2 & 0 & 26 & 19.2 \\
& BT23 & 0 & 0 & 2 & 3 & 0 & 1 & 8 & 0 & 15 & 57.1 \\
\multirow{5}{*}{$\Sigma$} & BT24 & 0 & 1 & 0 & 0 & 0 & 0 & 0 & 0 & 1 & 0.0 \\
UA & & 24 & 176 & 96 & 33 & 9 & 12 & 13 & 0 & 363 & \\
\hline
\end{tabular}

$\mathrm{BT}=$ building type (Figure 2), $\mathrm{PA}=$ producer's accuracy in \%, UA = user's accuracy in \%.

After the application of the refinement rules, the overall classification accuracy increased to $86.8 \%$ with user's and producer's accuracies over 75\% for most of the classes (Table 5). However, even with a manual refinement of the classes, a small class overlap could not be eliminated, especially between Single Family Standard (BT12) and Multi-Family Basic (BT21), as they are both characterized by one story and small to medium size. The table also shows that the Multi-Family Standard (BT22) has the lowest of all accuracies and is therefore probably underestimated in the prediction (only $43.8 \%$ producer's accuracy). However, based on its comparably low occurrence in Belmopan, this error is tolerable at the cost of high accuracies in the single family buildings. The same applies for Multi-Family Modern Apartment (BT24) which was not predicted by the classifier at all because of its low frequency in the training data $(n=1)$.

Table 5. Classification matrix of building types after the random forest classification.

\begin{tabular}{cccccccccccc}
\hline & & \multicolumn{1}{c}{ Classified } & & \multicolumn{1}{c}{$\sum$} & PA \\
\hline & & BT11 & BT12 & BT13 & BT14 & BT21 & BT22 & BT23 & BT24 & \\
& BT11 & $\mathbf{3 2}$ & 20 & 1 & 0 & 0 & 0 & 0 & 0 & 35 & 91.4 \\
& BT12 & 4 & $\mathbf{1 4 7}$ & 3 & 0 & 0 & 1 & 0 & 0 & 155 & 94.8 \\
& BT13 & 0 & 2 & $\mathbf{8 4}$ & 3 & 0 & 1 & 1 & 0 & 91 & 92.3 \\
real & BT14 & 1 & 2 & 2 & $\mathbf{2 5}$ & 1 & 1 & 0 & 0 & 32 & 78.1 \\
& BT21 & 1 & 4 & 1 & 2 & $\mathbf{1 0}$ & 1 & 0 & 0 & 19 & 52.6 \\
& BT22 & 0 & 2 & 3 & 2 & 0 & 7 & 2 & 0 & 16 & 43.8 \\
& BT23 & 0 & 0 & 2 & 2 & 0 & 1 & $\mathbf{1 0}$ & 0 & 14 & 71.4 \\
$\Sigma$ & BT24 & 0 & 1 & 0 & 0 & 0 & 0 & 0 & 0 & 1 & 0.0 \\
UA & & 38 & 160 & 96 & 33 & 9 & 12 & 13 & 0 & 363 & \\
\hline
\end{tabular}

$\mathrm{BT}=$ building type (Figure 2), $\mathrm{PA}=$ producer's accuracy in $\%, \mathrm{UA}=$ user's accuracy in $\%$.

After the assignment of new classes all 6627 building footprints were classified as demonstrated in Table 6, with Single Family Standard as the most frequent class (46\%). A total of 760 buildings were assigned to a primary non-residential use (public, commercial, industrial, uninhabited) based on the field survey and data from OpenStreetMap and Google Maps. It is however likely that there are even more non-residential buildings within the city which can be excluded from the socio-economic analyses. Building type 24 is present in Belmopan with minimal numbers. Therefore, it is challenging to characterize this building type in the training dataset with one sample. During data collection campaigns, the focus has solely been laid on residential building information. This leads especially to an underrepresentation of industrial used buildings, but as well other uses such as commerce, as a complete database for non-residential building use is not publicly available. Generally, single family buildings are classified more accurately than multi-family buildings. As dwelling numbers cannot be determined by remote sensing imagery, proxies such as building height must be applied. Even with a 
very high spatial resolution of $0.5 \mathrm{~m}$, the building heights derived by WV-1 can contain variations due to roof-covering vegetation, and other influences and therefore can lead to misclassification. The map in Figure 6 gives an overview on the building type classification in Belmopan.

Table 6. Building type information in Belmopan.

\begin{tabular}{ccc}
\hline Building Type & Number of Buildings & Share of Total Number \\
\hline 11-Single Family Basic & 764 & $11.5 \%$ \\
12-Single Family Standard & 3060 & $46.2 \%$ \\
13-Single Family Advanced & 1211 & $18.3 \%$ \\
14-Single Family Complex & 566 & $8.6 \%$ \\
21-Multi-Family Basic & 33 & $0.5 \%$ \\
22-Multi-Family Standard & 138 & $2.0 \%$ \\
23-Multi-Family Apartment & 94 & $1.4 \%$ \\
24-Multi-Family Modern Apartment & 1 & $<0.1 \%$ \\
Public & 166 & $2.5 \%$ \\
Commercial & 219 & $3.3 \%$ \\
Industrial & 6 & $<0.1 \%$ \\
Uninhabited & 369 & $5.5 \%$ \\
Total & 6627 & $100 \%$ \\
\hline
\end{tabular}
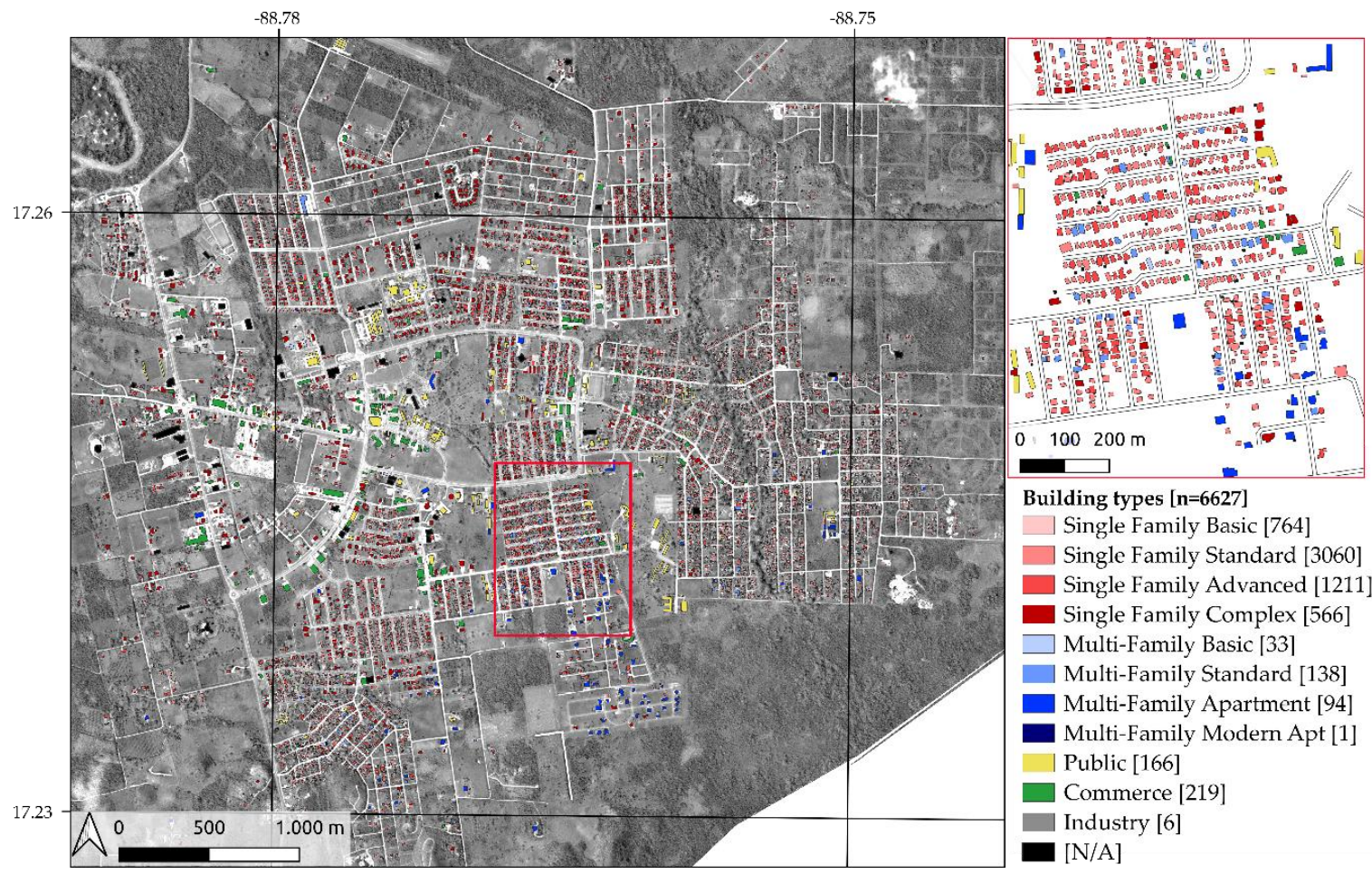

Figure 6. Map of detected buildings and classified building types in Belmopan (date: 2019/03/18). Total number of detected buildings: 6627. Manual assignment "Public", "Commerce", "Industry" on best knowledge. Background: PlanetLabs, 2018/03/18.; Stamen Design, Data by OpenStreetMap.

\subsection{Socio-Economic Points Determination}

The mean expenditures-normalized by the square root of the household size (corresponding to OECD recommendation [93]) — of the investigated households amount to $1320 \mathrm{BZD}$ per month ranging from less than $600 \mathrm{BZD}$ for the lower $25 \%$ of households to more than $1450 \mathrm{BZD}$ per month for the upper 25\%. The median expenditures were 930 BZD per month. As can be seen in Figure 5, roughly half of the monthly expenditures are on food (27\%) and housing including additional costs 
(22\%). Other major spending factors are medical care $(16 \%)$ which include medicine, doctor's visits and health insurance, and mobility (15\%).

As a second category of the socio-economic index, items owned by the households (assets) were considered. Within this category various items and features were queried, of which 24 selected assets were determined to be included into the index. Figure $7 \mathrm{~b}$ shows these 24 main assets and the percentage of households that own them. As one can see, there are some assets that the majority of the surveyed households own like a stove (98\%) or an electric fan (95\%) but also assets that are relatively rare like a dishwasher $(13 \%)$ or a generator $(5 \%)$.

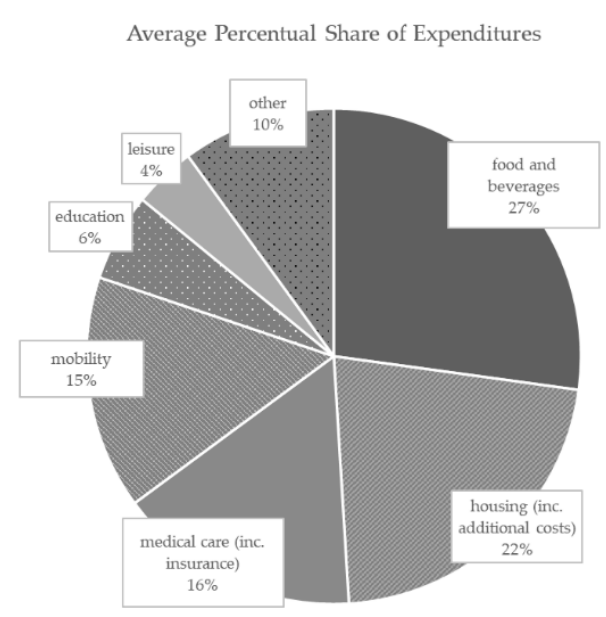

(a)

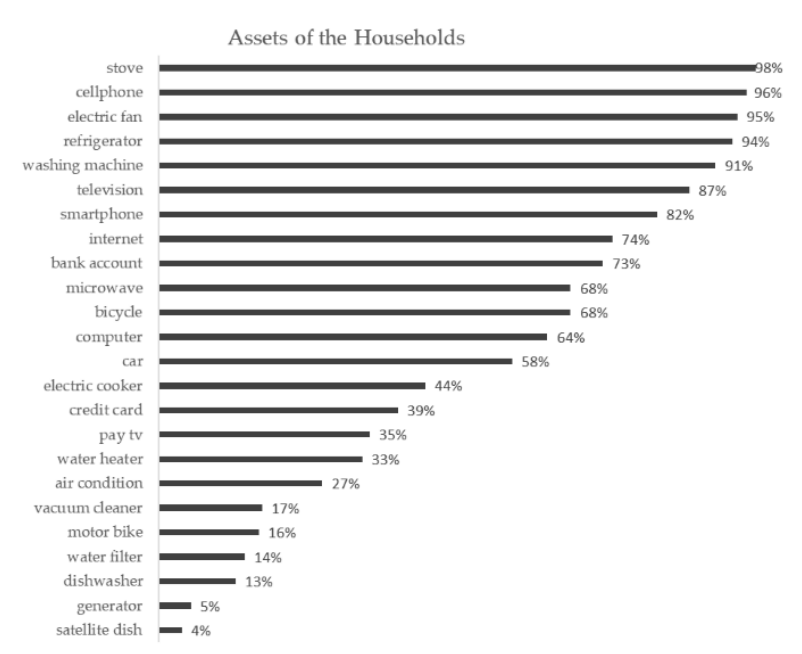

(b)

Figure 7. Percentage share of household expenditures (a) and household assets (b) in Belmopan ( $n=395$ interviews).

The third category considers educational degrees. With the "associate's degree" as the first university degree in Belize, six different educational levels were identified for Belmopan ranging from no school graduation (educational class 1) to master's degree or higher (educational class 6). Figure 8 shows the shares of the educational levels of the main income earners of the households in the surveyed areas. About a quarter of the main income earners in the interviewed households have only primary school graduation (17\%) or no school graduation at all (10\%), in contrast to the $45 \%$ that hold a university degree (associate's degree 17\%, 18\% bachelor's degree, 10\% master's degree or higher). Figure 8 gives an overview on the educational degrees of the main income earners in Belmopan. 


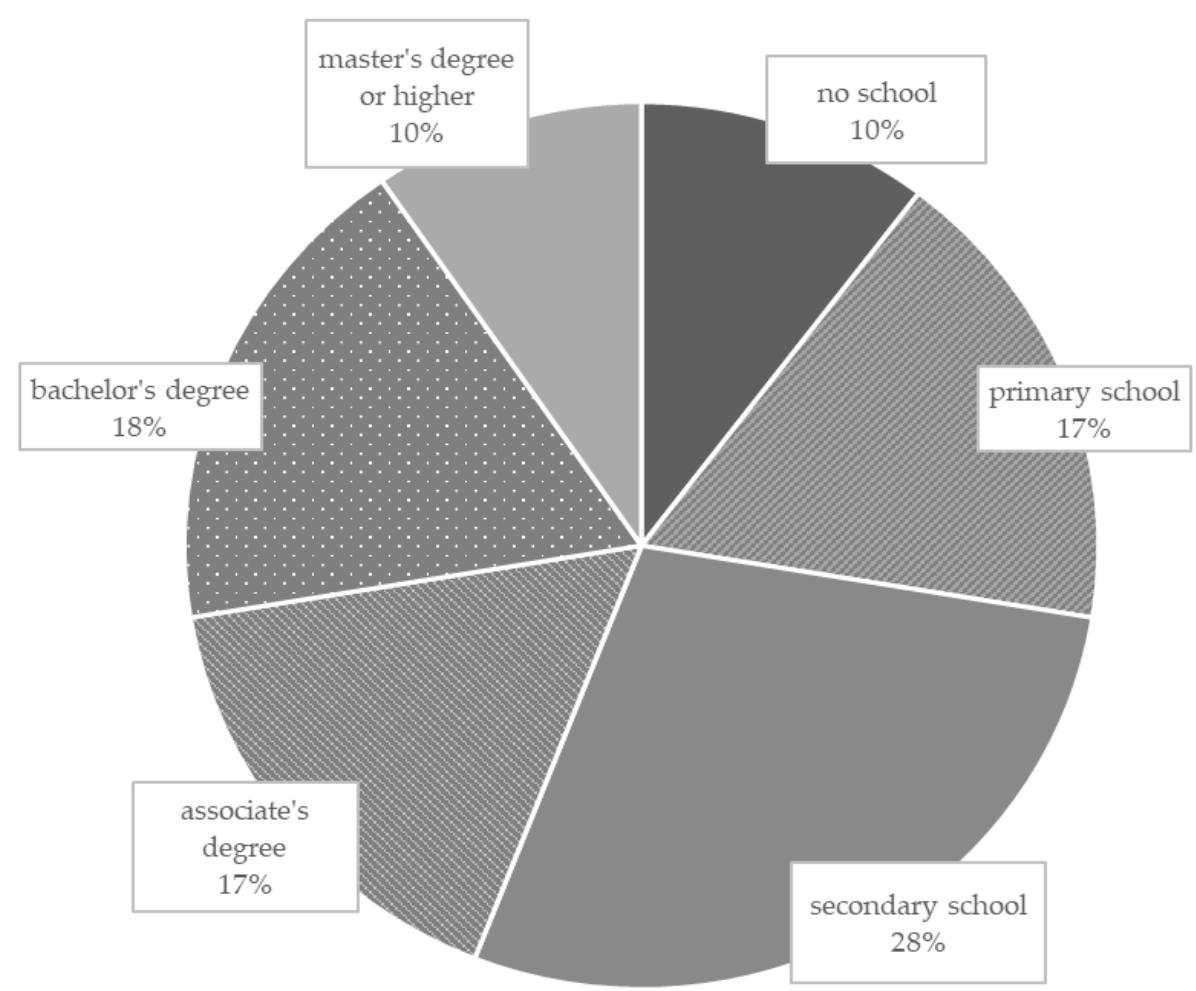

Figure 8. Educational degree for main income earner in Belmopan ( $n=395$ interviews).

Based on the developed socio-economic index (see Section 2.2.6.) the socio-economic points (SEP) were derived by the results of the three categories. The average socio-economic points of the 395 investigated households is 10.5. The distribution of the SEPs is shown in Figure 9. Appendix C provides a summary of the composition of SEP based on the three used components per building type.

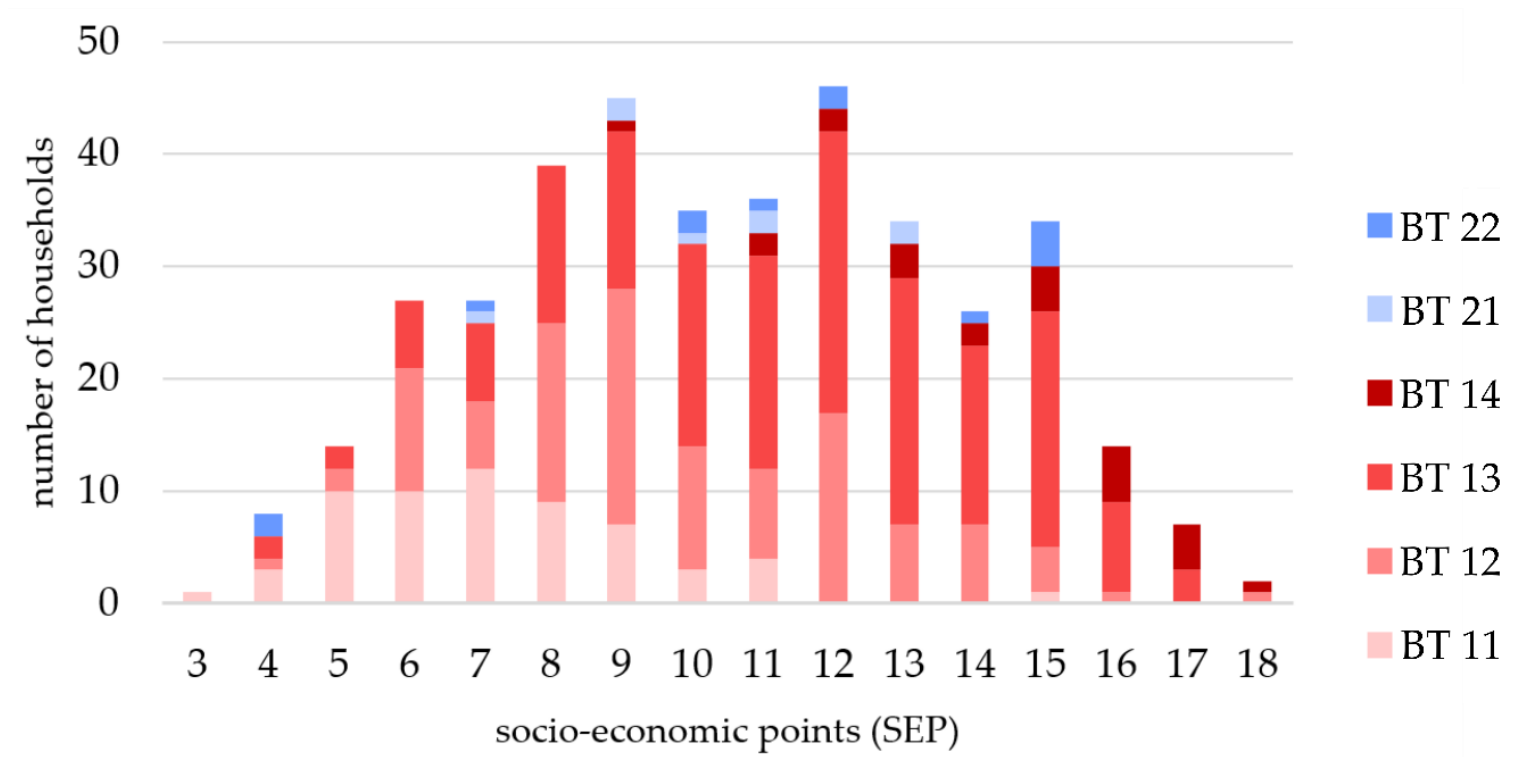

Figure 9. Histogram showing the statistical distribution of residential socio-economic points on household level in Belmopan. Data based on interviews.

\subsection{Class Generation and Extrapolation}

As Figure 10a shows, building types can be described by SEP. However, building types 12, 13 , and 22 show high variations of socio-economic points. This leads to imprecise socio-economic 
predictions. To reduce this variation, building types 12,13 , and 22 needed to be disaggregated in subclasses $12 a / 12 b, 13 a / 13 b$, and $22 a / 22 b$. A set of best fitting spatial indicators were tested to serve as parameters for splitting the building types. Table A1 in Appendix D shows the relationships between intra-building type socio-economic measures and spatial indicators. Distance to market center, distance between the ring road and building, the share of buildings within a 250-m hexagon, delivered the best results. For building type 13, the distance to the US Embassy showed with an $r=-0.33$ the highest correlation coefficient to the decline of socio-economic measures compared to the other quality of life indicators tested with a $p=0.00001$ showing high significance (Figure 11b). The correlation analysis between the SEP (BT22) and share of built-up area parameter revealed an $r=0.44$, but a relatively high $p=0.15$. This is due to the small sample size, but the obvious trend can be seen. Figure 11 shows the correlations between the spatial indicators and socio-economic measures within building types 12, 13, and 22. An overview on thresholds for building type separation and socio-economic statistics for the building types is given in Appendix E.

SEP statistics for initial and refined building types
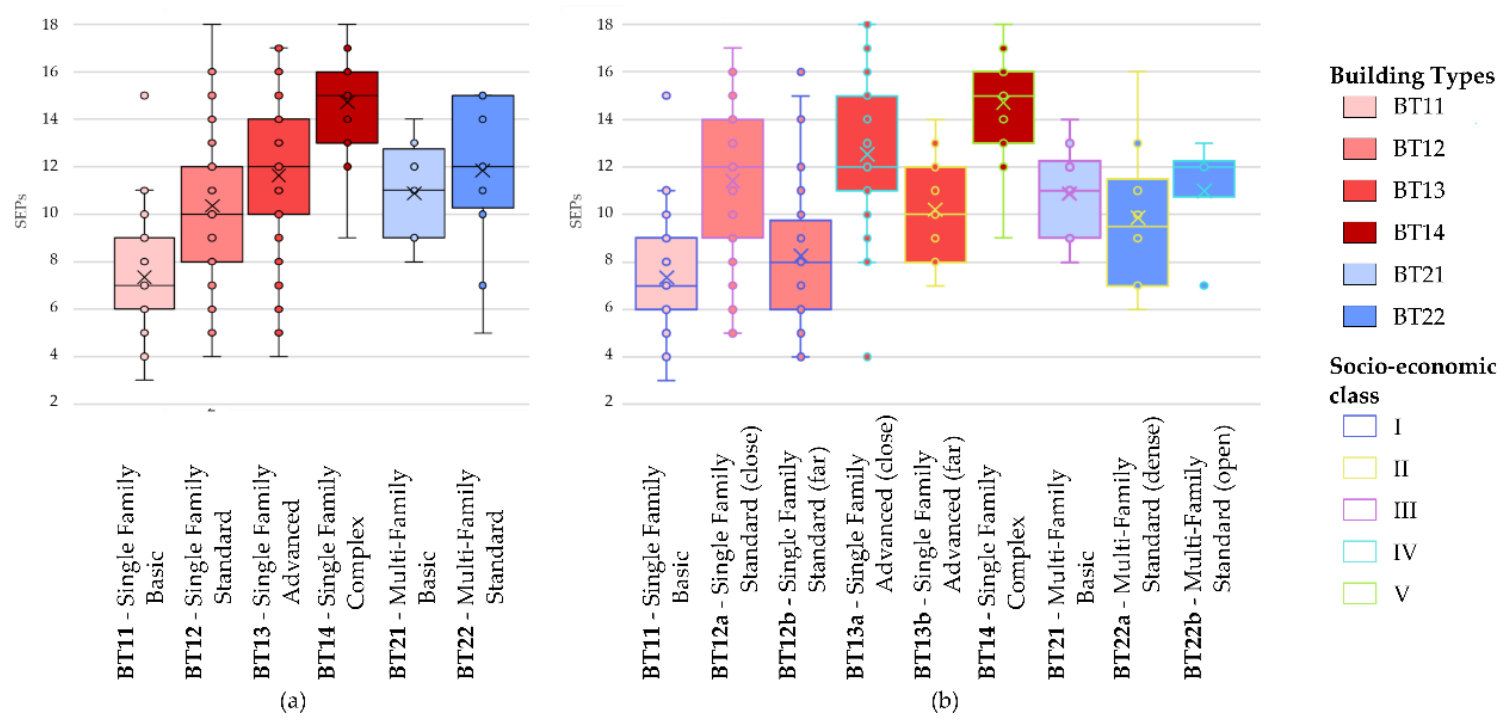

Figure 10. Boxplot chart showing statistical distribution of SEPs over building types. (a) Initial building typology with high SEP variation in building type classes 12,13, and 22. (b) The statistical distribution of SEP on refined building typology with effect of reduced variation of SEP for the building type classes $12 \mathrm{a} / \mathrm{b}, 12 \mathrm{a} / \mathrm{b}$, and $22 \mathrm{a} / \mathrm{b}$. In (b), socio-economic class (SEC) assignment is indicated by colored contours (SEC I: blue, SEC II: yellow, SEC III: pink, SEC IV turquoise, SEC V: green). For detailed statistics see Appendix E.

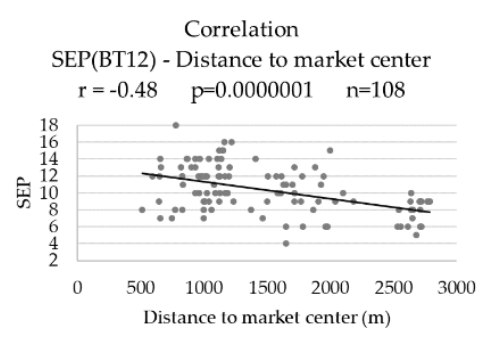

(a)

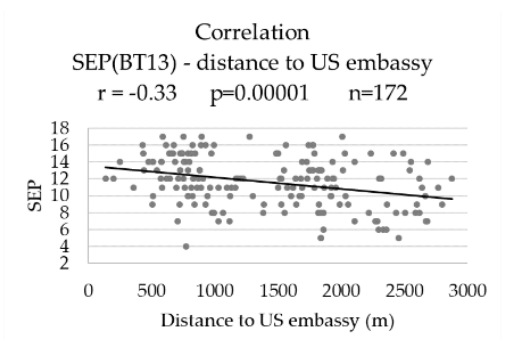

(b)

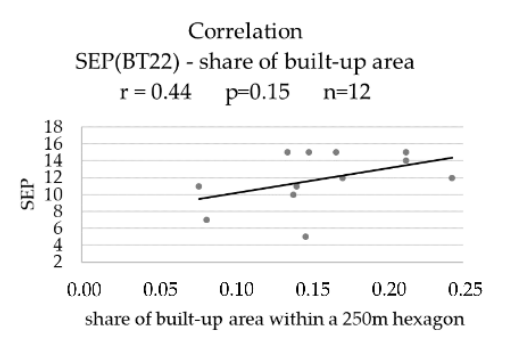

(c)

Figure 11. Identified effects of distance on SEP within building types to be disaggregated in Belmopan. For each relation $(\mathbf{a}-\mathbf{c})$ the correlation coefficient $r$ is given, as well as statistical significance $p$ and sample size $n$. 
As described in Section 2.2.7, there is a necessity to create socio-economic classes for three reasons:

1. To predict socio-economic relevant planning values on a single building scale based on building type;

2. To avoid a false impression of precision;

3. Not to publish detailed sensitive information on resident's socio-economic status at a single building level.

The classes were chosen considering the SEP statistics of the building types. On this basis, the classes were assigned manually. We chose to establish five socio-economic classes, with the effect that not every building type represents a single socio-economic class, for which there is no need. Main decision criteria are the highest possible homogeneity in SEP. By comparing mean socio-economic points and standard deviations of SEP within the building types, we set up the class assignment shown in Table 7, which meets the stated criteria for homogeneity in SEPs.

Table 7. Table on assignment of socio-economic classes to building types and number of buildings to corresponding building type classes and socio-economic classes.

\begin{tabular}{|c|c|c|}
\hline Socio-Economic Class & Building Types & Number of Buildings \\
\hline \multirow{2}{*}{ I } & 11 & 764 \\
\hline & $12 \mathrm{far}$ & 2573 \\
\hline \multirow{2}{*}{ II } & 13 far & 792 \\
\hline & 22 dense & 80 \\
\hline \multirow{2}{*}{ III } & 12 close & 487 \\
\hline & 21 & 33 \\
\hline \multirow{2}{*}{ IV } & 13 close & 419 \\
\hline & 22 open & 58 \\
\hline $\mathrm{V}$ & 14 & 566 \\
\hline Total number of residential bu & & 5772 \\
\hline
\end{tabular}

Based on these assignment rules, the socio-economic class was predicted for residential buildings. Figure 12 gives an graphical example for building types and the referring SEC in Belmopan.

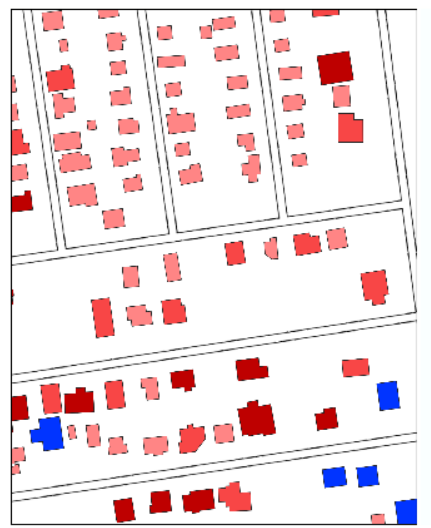

(a)

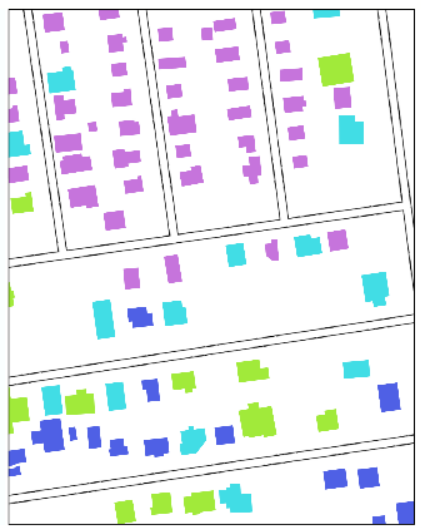

(b)
Building Types

$\square$ Single Family Basic

- Single Family Standard

Single Family Advanced

Single Family Complex

\ Multi Family Basic

$\square$ Multi Family Standard

Multi Family Apartment

Multi Family Modern Apartment

Socio-economic classes (SEC)

I

II

III

IV
V

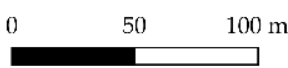

Figure 12. SEC prediction based on building types. (a) Building types, (b) SEC assignment based on rules shown in Table 7. Upper part in the legend showing building types referring to (a), lower part of the legend showing SEC referring to $(\mathbf{b})$. 


\section{Discussion}

Basing on building footprints, building types can be classified with random forest in high accuracy. Besides footprint area, a database of ancillary data for three-dimensional building description, spatial information, and rule-based adaptions are essential for successful classification results, as shown in Appendix B.

The intended and applied interview design based on a spatial sampling method that defines areas for interviews using areas of major building type abundances enables the socio-economic characterization for Belmopan. The establishment of the SEP as index to describe residential socio-economic backgrounds delivers good results by combining information on expenditure, educational level, assets, and household income. Correlations between building types and socio-economic information could be proven in this study. For predicting socio-economic attributes, we think it is necessary to create socio-economic classes. Predicting a socio-economic 15-part scale generates too much room for decreased accuracy, therefore a socio-economic classification containing five classes represents socio-economic information in relation to building types with sufficient information content.

The success of the work is directly linked to the collaboration with local authorities and in situ interviews. Our study showed that the implementation of local knowledge is essential to the result for multiple reasons:

1. The establishment of the building typology needs to be adapted for individual case cities. High variations in building types can even exist within countries;

2. The generation of socio-economic information and a socio-economic scaling, SEP in our study, must be based on local information and current surveys;

3. This work indirectly confirms findings of previous studies on location-dependent land value $[31,94]$ through high variation of SEP within single building types. By applying spatial measures, building types can be disaggregated to achieve building types homogenous in SEPs. To identify reference points of urban function, local knowledge is needed as well.

As the relation between building types and socio-economic categorization is shown, it is possible to characterize municipalities for supply and infrastructure planning. Socio-economic information is not directly utilizable as planning value, but the relation between consumption/waste production and socio-economy has been shown [6-10]. Furthermore, the interview design allows conclusion on household assets-on which energy demands can be estimated. Knowledge on building types can support describing and predicting socio-economic attributes. As the socio-economic classification is an a-posteriori measure, a focus should be put on validating the socio-economic measures.

The presented methodology is not limited to WV-1 data. Other VHR imaging satellites can be implemented for building detection and building type classification, which offer a high flexibility for data generation, especially for upcoming satellites missions such as Pléiades Neo [74] and the WorldView Legion [75]. A higher number of VHR imaging satellites leads to increased data availability and higher data reliability. As a result of this, our presented approach is able to continue in operation for long-term urban mapping and planning.

Nonetheless, an awareness must be created that with using VHR imaging technology, data producers and data users are moving on both sides of the borderline of personal privacy and space. The presented methodology produces sensitive information, which can in incautious motivations help expose certain groups of inhabitants or, respectively, induce or increase social conflicts. Discussions must be conducted on how to handle this level of information in general. 


\section{Conclusions}

Our presented methodology proved to be able to provide valuable relevant socio-economic indicators for planning. VHR remote sensing data and in-situ household interviews are essential for high accuracy results. For larger municipalities, other building detection approaches must be used to reduce processing time and manual corrections. Regarding this, techniques basing on machine learning have shown their potential for fast processing of large amounts of satellite imagery [26,30].

Considering Zhu's demand for future strategic directions in urban remote sensing to contribute to the use remote sensing techniques for the "characterization of urban heterogeneity, characterization of urban form and structure in two and three dimensions, and linking remote sensing with emerging urban data" [96], this study works in this manner and shows a way to implement VHR remote sensing data for urban infrastructure planning and delivers information to support evidence based planning [4]. As previously shown, the availability of satellite imagery will increase and therefore a constant data availability will be established. Furthermore, the potential of unmanned aerial vehicles (UAVs) for the quick and cost-effective mapping of urban areas can be exploited even more [97]. The findings of this study, to predict socio-economic information by using VHR images, have shown the potential to support urban planning. Subsequently, we see a necessity to do further investigation on the suitability of such data to derive relevant information for direct planning from similar databases. With knowledge regarding building parameters, such as building height and roof information, and having access to building type and socio-economic information on residents, further attempts should be made to predict specific consumption and production patterns, such as energy demands, waste water production, and solid waste production as Vetter-Gindele [87] has shown for waste production.

Author Contributions: Conceptualization, G.W.; methodology, G.W., A.B., O.A.; validation, A.B., G.W., V.H., O.A., K.F.; formal analysis, G.W., A.B., O.A., K.F.; investigation, G.W.; data curation, G.W., A.B., K.F.; writing-original draft preparation, G.W.; writing-review and editing, G.W., A.B., O.A.; visualization, G.W., A.B., K.F.; supervision, V.H., O.A.; project administration, V.H., O.A.; funding acquisition, V.H., O.A. All authors have read and agreed to the published version of the manuscript.

Funding: This research was funded by the German Federal Ministry of Education and Research (BMBF) under the project "RapidPlanning" (grant identifier 01LG1301K). We acknowledge support by Deutsche Forschungsgemeinschaft and Open Access Publishing Fund of University of Tübingen.

Acknowledgments: We thank Dieter Steinbach and Andrea Schultheis from AT-Association for developing and bringing up the idea of deriving planning relevant information with relevance of building types. Many thanks to the Belmopan City Council for their hospitality, as well as for the fruitful and professional collaboration which made this work possible, including the provision of data and the tireless support during our field work. Special thanks to Paul Wehrle, who organized, supervised, and conducted the interview campaign in 2019. We are very grateful for the language advising provided by Edward III Cahill. PlanetScope data was kindly provided by Planet with the Education and Research program.

Conflicts of Interest: The authors declare no conflict of interest. 


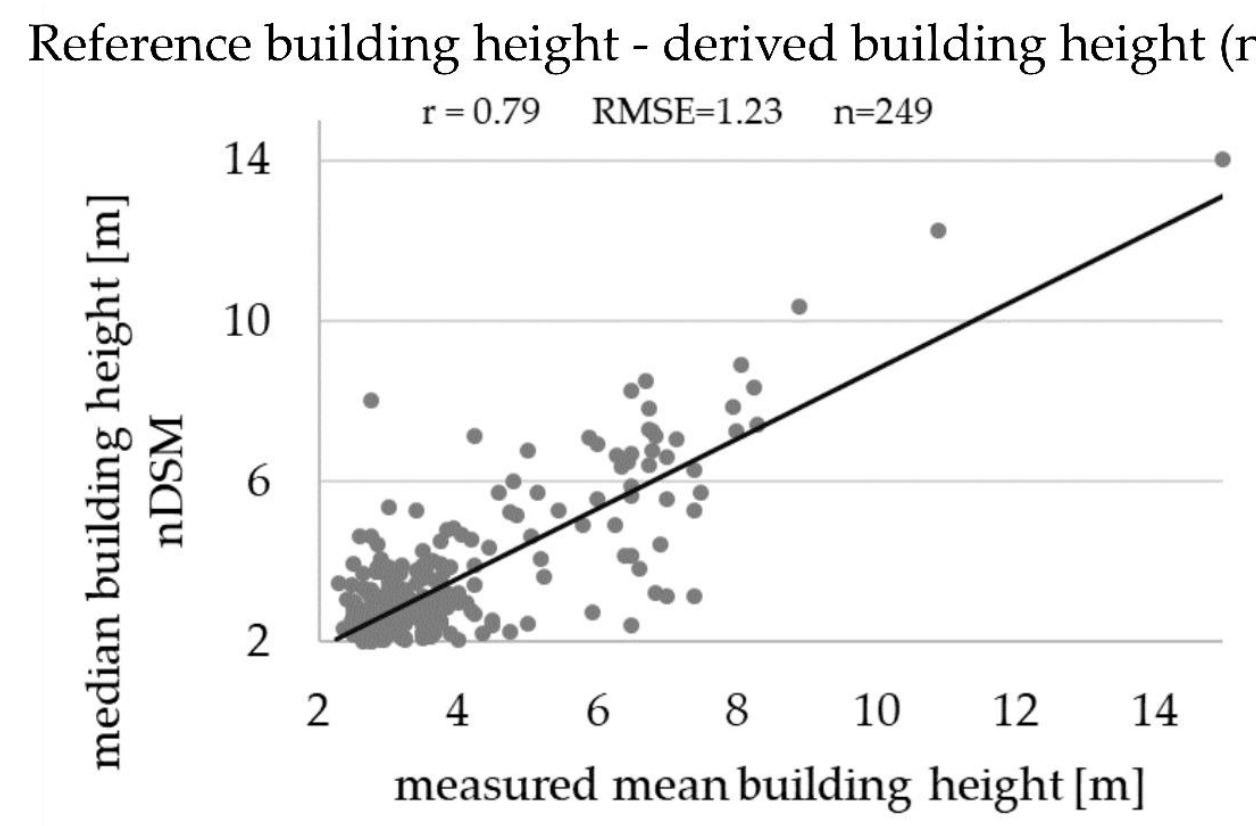

Figure A1. Validation for determined building heights from WV-1 nDSM. The reference dataset was generated by 249 measured buildings. The mean building represents the mean height from wall height and rooftop height.

\section{Appendix B. Manual Refinement of Building Type Classifications}

IF BT12 AND area $<125$ THEN BT11

IF BT13 AND corners $>7$ THEN BT12

IF BT12 AND area $>150$ AND height $>4$ THEN BT13

IF BT13 AND area $<140$ AND height $<3.15$ THEN BT12

IF BT13 AND shape_ratio $>3.05$ THEN BT14

IF BT21 AND corners $>4 A N D$ area $<220$ THEN BT13

IF BT22 AND corners $<6$ AND height $<3.9$ THEN BT12

IF BT22 AND corners $>6$ AND area $<350$ THEN BT14

IF BT23 AND height $>5.25$ THEN BT14

IF BT1x AND area $>150$ AND height $>3.05$ THEN BT21

IF BT14 AND corners $<7$ AND area $>145$ THEN BT22

IF BT14 AND height $>5.15$ ABD AREA $>190$ THEN BT23

IF BT11 AND ('Elysium' OR 'Florida' OR 'Maya Ketchi' OR 'Maya Mopan' OR 'Maya Yucatec' OR 'Utopian' OR 'Salvapan' OR 'North Salvapan' OR 'San Martin') THEN BT12

IF BT1x AND perimeter $>47$ AND height $>3.7$ AND corners $>7$ AND shape_ratio $>3.4$ AND area $>230$ THEN BT14

IF BT1x AND area $<30$ THEN uninhabited

IF BT1x AND area $>510$ AND corners $\leq 5$ THEN uninhabited

uninhabited

"btype_complete" like “\%Single\%' and "shp_area" > 510 and "shp_corners" <= 5

"shp_area" < 30

Single Family Advanced

"btype_complete" = 'Single Family Standard' and "hgt_building" > 4 and "shp_area" > 150 
Appendix C. Figure Showing Socio-Economic Points Composition per Building Type

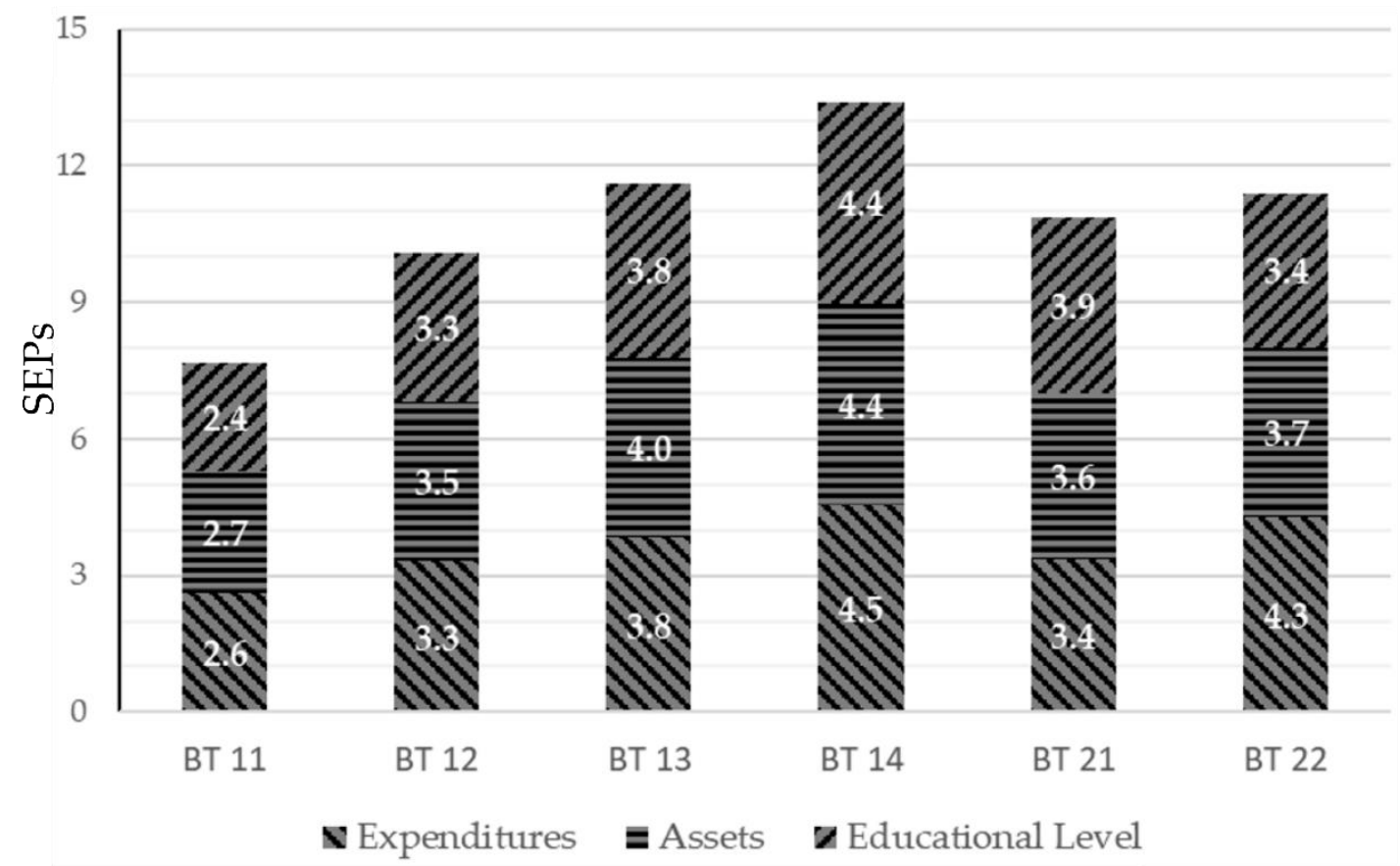

Figure A2. SEPs per building type. As described in Section 2.2.6, total SEP are composed of household expenditures, household assets, and educational level of household main earner.

\section{Appendix D. Table Showing Correlation between SEP and Distances from Urban Points of Centrality}

Table A1. Relation between distance from buildings to point urban centrality to socio-economy on building type level.

\begin{tabular}{ccccc}
\hline SEP (Building Type Level) & $\begin{array}{c}\mathbf{r} \\
\text { Ringroad }\end{array}$ & $\begin{array}{c}\mathbf{r} \\
\text { Center }\end{array}$ & $\begin{array}{c}\mathbf{r} \\
\text { US Embassy }\end{array}$ & $\begin{array}{c}\mathbf{r} \\
\text { Built-Up 250 m }\end{array}$ \\
\hline \multirow{2}{*}{ 12-Single Family Standard } & -0.47 & $-\mathbf{0 . 4 8}$ & -0.44 & 0.29 \\
& $\left(p=1.8^{*} 10^{-7}\right)$ & $\left(p=1.1^{*} 10^{-7}\right)$ & $\left(p=1.4^{*} 10^{-6}\right)$ & $(p=0.002)$ \\
13-Single Family Advanced & -0.19 & -0.27 & $-\mathbf{0 . 3 3}$ & 0.05 \\
& $(p=0.01)$ & $(p=0.0004)$ & $\left(p=1.2^{*} 10^{-5}\right)$ & $(p=0.5)$ \\
22-Multi-Family Standard & -0.30 & -0.43 & -0.19 & $\mathbf{0 . 4 4}$ \\
& $(p=0.33)$ & $(p=0.15)$ & $(p=0.55)$ & $(p=0.15)$ \\
\hline
\end{tabular}




\section{Appendix E. Overview on Parameters for Disaggregating Building Types 12, 13, and 22}

Table A2. Overview on thresholds for building type disaggregation and socio-economic statistics on refined building types. Thresholds for building type disaggregation apply to BT12: distance to market center, BT13: distance to US embassy, BT22: share of built-up area within a $250 \mathrm{~m}$ hexagon.

\begin{tabular}{ccccc}
\hline Initial Building Types & $\boldsymbol{n}$ & Mean SEP & Standard Deviation SEP & Threshold \\
\hline 12-Single Family Standard & 108 & 10.4 & 2.79 & $988 \mathrm{~m}$ \\
13-Single Family Advanced & 172 & 11.6 & 2.94 & $1018 \mathrm{~m}$ \\
22-Multi-Family Standard & 12 & 11.8 & 3.30 & 0.125 \\
\hline Refined Building types & $\boldsymbol{n}$ & Mean SEP & Standard Deviation SEP \\
\hline 11-Single Family basic & 55 & 7.3 & 2.2 \\
12a-Single Family Standard close & 74 & 11.3 & 2.59 \\
12b-Single Family Standard far & 34 & 8.3 & 1.99 \\
13a-Single Family Advanced close & 69 & 12.8 & 2.6 \\
13b-Single Family Advanced far & 103 & 10.9 & 2.9 \\
14-Single Family complex & 24 & 14.7 & 2.1 \\
22a-Multi-Family Advanced open & 6 & 13.8 & 1.47 & \\
22b-Multi-Family Advanced dense & 6 & 9.8 & 3.48 \\
23-Multi-Family Apartment & 1 & 15 & - \\
\hline
\end{tabular}

Thresholds applied to following parameters: Building type 12: "distance to ring road (in meters)", building type 12: "distance to market center (in meters)", building type 22: "shared built-up area within a $250 \mathrm{~m}$ hexagon".

\section{References}

1. United Nations Department of Economic Social Affairs. World Urbanization Prospects: The 2018 Revision; United Nations: New York, NY, USA, 2018.

2. Cohen, B. Urbanization in developing countries: Current trends, future projections, and key challenges for sustainability. Technol. Soc. 2006, 28, 63-80. [CrossRef]

3. UN General Assembly. Transforming Our World: The 2030 Agenda for Sustainable Development; United Nations: New York, NY, USA, 2015.

4. Guterres, A. Actions for the Further Implementation of the Programme of Action of the International Conference on Population and Development: Monitoring of Population Programmes, Focusing on Sustainable Cities, Human Mobility and International Migration; United Nations Economic and Social Council: New York, NY, USA, 2018.

5. United Nations Human Settlements Programme. Planning Sustainable Cities: Global Report on Human Settlements 2009; Earthscan: London, UK, 2009.

6. Oribe-Garcia, I.; Kamara-Esteban, O.; Martin, C.; Macarulla-Arenaza, A.M.; Alonso-Vicario, A. Identification of influencing municipal characteristics regarding household waste generation and their forecasting ability in Biscay. Waste Manag. 2015, 39, 26-34. [CrossRef] [PubMed]

7. Khan, D.; Kumar, A.; Samadder, S.R. Impact of socioeconomic status on municipal solid waste generation rate. Waste Manag. 2016, 49, 15-25. [CrossRef] [PubMed]

8. Xu, L.; Lin, T.; Xu, Y.; Xiao, L.; Ye, Z.; Cui, S. Path analysis of factors influencing household solid waste generation: A case study of Xiamen Island, China. J. Mater. Cycles Waste Manag. 2016, 18, 377-384. [CrossRef]

9. Bosire, E.; Oindo, B.; Atieno, J.V. Modeling Household Solid Waste Generation in Urban Estates Using SocioEconomic and Demographic Data; Maseno University: Kisumu City, Kenya, 2017.

10. Jones, R.V.; Fuertes, A.; Lomas, K.J. The socio-economic, dwelling and appliance related factors affecting electricity consumption in domestic buildings. Renew. Sustain. Energy Rev. 2015, 43, 901-917. [CrossRef]

11. Brown de Colstoun, E.C.; Huang, C.; Wang, P.; Tilton, J.C.; Tan, B.; Phillips, J.; Niemczura, S.; Ling, P.-Y.; Wolfe, R.E. Global Man-made Impervious Surface (GMIS) Dataset from Landsat; NASA Socioeconomic Data and Applications Center (SEDAC): Palisades, NY, USA, 2017.

12. Zhou, Y.; Smith, S.J.; Zhao, K.; Imhoff, M.; Thomson, A.; Bond-Lamberty, B.; Asrar, G.R.; Zhang, X.; He, C.; Elvidge, C.D. A global map of urban extent from nightlights. Environ. Res. Lett. 2015, 10, 054011. [CrossRef] 
13. Esch, T.; Marconcini, M.; Felbier, A.; Roth, A.; Heldens, W.; Huber, M.; Schwinger, M.; Taubenböck, H.; Müller, A.; Dech, S. Urban Footprint Processor-Fully Automated Processing Chain Generating Settlement Masks From Global Data of the TanDEM-X Mission. IEEE Geosci. Remote Sens. Lett. 2013, 10, 1617-1621. [CrossRef]

14. Esch, T.; Heldens, W.; Hirner, A.; Keil, M.; Marconcini, M.; Roth, A.; Zeidler, J.; Dech, S.; Strano, E. Breaking new ground in mapping human settlements from space-The Global Urban Footprint. ISPRS J. Photogramm. Remote Sens. 2017, 134, 30-42. [CrossRef]

15. Marconcini, M.; Metz-Marconcini, A.; Uereyen, S.; Palacios Lopez, D.; Hanke, W.; Bachofer, F.; Zeidler, J.; Esch, T.; Gorelick, N.; Kakarla, A.; et al. Outlining Where Humans Live-The World Settlement Footprint 2015. Available online: https://arxiv.org/abs/1910.12707 (accessed on 11 November 2019).

16. Warth, G.; Braun, A.; Bödinger, C.; Hochschild, V.; Bachofer, F. DSM-based identification of changes in highly dynamic urban agglomerations. Eur. J. Remote Sens. 2019, 52, 322-334. [CrossRef]

17. Braun, A.; Warth, G.; Bachofer, F.; Bui, T.; Tran, H.; Hochschild, V. Changes in the building stock of DaNang between 2015 and 2017. Data 2020, 5, 42. [CrossRef]

18. Blaschke, T. Object based image analysis for remote sensing. ISPRS J. Photogramm. Remote Sens. 2010, 65, 2-16. [CrossRef]

19. Dey, V.; Zhang, Y.; Zhong, M. Building detection from pan-sharpened GeoEye-1 satellite imagery using context based multi-level image segmentation. In Proceedings of the 2011 International Symposium on Image and Data Fusion, Tengchong, China, 9 August 2011; pp. 1-4.

20. Grippa, T.; Lennert, M.; Beaumont, B.; Vanhuysse, S.; Stephenne, N.; Wolff, E. An Open-Source Semi-Automated Processing Chain for Urban Object-Based Classification. Remote Sens. 2017, 9, 358. [CrossRef]

21. Banzhaf, E.; Kollai, H.; Kindler, A. Mapping urban grey and green structures for liveable cities using a 3D enhanced OBIA approach and vital statistics. Geocarto Int. 2018, 35, 1-18. [CrossRef]

22. Sari, N.M.; Kushardono, D. Quality Analysis of Single Tree Object with OBIA and Vegetation Index from LAPAN Surveillance Aircraft Multispectral Data in Urban Area. Geoplanning J. Geomat. Plan. 2016, 3, 93-106. [CrossRef]

23. Labib, S.M.; Harris, A. The potentials of Sentinel-2 and LandSat-8 data in green infrastructure extraction, using object based image analysis (OBIA) method. Eur. J. Remote Sens. 2018, 51, 231-240. [CrossRef]

24. Banzhaf, E.; de la Barrera, F. Evaluating public green spaces for the quality of life in cities by integrating RS mapping tools and social science techniques. In Proceedings of the 2017 Joint Urban Remote Sensing Event (JURSE), Dubai, UAE, 6-8 March 2017; pp. 1-4.

25. LeCun, Y.; Huang, F.J.; Bottou, L. Learning methods for generic object recognition with invariance to pose and lighting. In Proceedings of the 2004 IEEE Computer Society Conference on Computer Vision and Pattern Recognition, 2004. CVPR 2004, Washington, DC, USA, 27 June-2 July 2004; pp. II-104.

26. Vakalopoulou, M.; Karantzalos, K.; Komodakis, N.; Paragios, N. Building detection in very high resolution multispectral data with deep learning features. In Proceedings of the 2015 IEEE International Geoscience and Remote Sensing Symposium (IGARSS), Milan, Italy, 26-31 July 2015; pp. 1873-1876.

27. Persello, C.; Stein, A. Deep Fully Convolutional Networks for the Detection of Informal Settlements in VHR Images. IEEE Geosci. Remote Sens. Lett. 2017, 14, 2325-2329. [CrossRef]

28. Liu, R.; Kuffer, M.; Persello, C. The Temporal Dynamics of Slums Employing a CNN-Based Change Detection Approach. Remote Sens. 2019, 11, 2844. [CrossRef]

29. Xia, X.; Persello, C.; Koeva, M. Deep Fully Convolutional Networks for Cadastral Boundary Detection from UAV Images. Remote Sens. 2019, 11, 1725. [CrossRef]

30. Zhu, X.X.; Tuia, D.; Mou, L.; Xia, G.; Zhang, L.; Xu, F.; Fraundorfer, F. Deep Learning in Remote Sensing: A Comprehensive Review and List of Resources. IEEE Geosci. Remote Sens. Mag. 2017, 5, 8-36. [CrossRef]

31. Brimble, P.; McSharry, P.; Bachofer, F.; Bower, J.; Braun, A. Using Machine Learning and Remote Sensing to Value Property in Kigali; The International Growth Centre: London, UK, 2020.

32. Mikhail, E.M.; Bethel, J.S.; McGlone, J.C. Introduction to Modern Photogrammetry; Wiley: New York, NY, USA, 2001.

33. Bachofer, F. Assessment of building heights from pléiades satellite imagery for the Nyarugenge sector, Kigali, Rwanda. Rwanda J. 2017, 1. [CrossRef]

34. Dong, P.; Chen, Q. LiDAR Remote Sensing and Applications; CRC Press: Boca Raton, FL, USA, 2017. 
35. Liu, L.; Coops, N.C.; Aven, N.W.; Pang, Y. Mapping urban tree species using integrated airborne hyperspectral and LiDAR remote sensing data. Remote Sens. Environ. 2017, 200, 170-182. [CrossRef]

36. Alonzo, M.; McFadden, J.P.; Nowak, D.J.; Roberts, D.A. Mapping urban forest structure and function using hyperspectral imagery and lidar data. Urban For. Urban Green. 2016, 17, 135-147. [CrossRef]

37. Giannico, V.; Lafortezza, R.; John, R.; Sanesi, G.; Pesola, L.; Chen, J. Estimating Stand Volume and Above-Ground Biomass of Urban Forests Using LiDAR. Remote Sens. 2016, 8, 339. [CrossRef]

38. Lafortezza, R.; Giannico, V. Combining high-resolution images and LiDAR data to model ecosystem services perception in compact urban systems. Ecol. Indic. 2019, 96, 87-98. [CrossRef]

39. Zhang, H.; Lin, H.; Wang, Y. A new scheme for urban impervious surface classification from SAR images. ISPRS J. Photogramm. Remote Sens. 2018, 139, 103-118. [CrossRef]

40. Crosetto, M.; Castillo, M.; Arbiol, R. Urban subsidence monitoring using radar interferometry. Photogramm. Eng. Remote Sens. 2003, 69, 775-783. [CrossRef]

41. Potin, P.; Rosich, B.; Miranda, N.; Grimont, P.; Shurmer, I.; O'Connell, A.; Krassenburg, M.; Gratadour, J.-B. Copernicus Sentinel-1 Constellation Mission Operations Status. In Proceedings of the IGARSS-2019 IEEE International Geoscience and Remote Sensing Symposium, Yokohama, Japan, 28 July-2 August 2019; pp. 5385-5388.

42. Gabriel, A.K.; Goldstein, R.M.; Zebker, H.A. Mapping small elevation changes over large areas: Differential radar interferometry. J. Geophys. Res. Solid Earth 1989, 94, 9183-9191. [CrossRef]

43. Notti, D.; Mateos, R.M.; Monserrat, O.; Devanthéry, N.; Peinado, T.; Roldán, F.J.; Fernández-Chacón, F.; Galve, J.P.; Lamas, F.; Azañón, J.M. Lithological control of land subsidence induced by groundwater withdrawal in new urban areas (Granada Basin, SE Spain). Multiband DInSAR monitoring. Hydrol. Process. 2016, 30, 2317-2331. [CrossRef]

44. Cascini, L.; Ferlisi, S.; Fornaro, G.; Lanari, R.; Peduto, D.; Zeni, G. Subsidence monitoring in Sarno urban area via multi-temporal DInSAR technique. Int. J. Remote Sens. 2006, 27, 1709-1716. [CrossRef]

45. Chaussard, E.; Amelung, F.; Abidin, H.; Hong, S.-H. Sinking cities in Indonesia: ALOS PALSAR detects rapid subsidence due to groundwater and gas extraction. Remote Sens. Environ. 2013, 128, 150-161. [CrossRef]

46. Tesauro, M.; Berardino, P.; Lanari, R.; Sansosti, E.; Fornaro, G.; Franceschetti, G. Urban subsidence inside the city of Napoli (Italy) Observed by satellite radar interferometry. Geophys. Res. Lett. 2000, 27, 1961-1964. [CrossRef]

47. Delgado Blasco, J.M.; Foumelis, M.; Stewart, C.; Hooper, A. Measuring Urban Subsidence in the Rome Metropolitan Area (Italy) with Sentinel-1 SNAP-StaMPS Persistent Scatterer Interferometry. Remote Sens. 2019, 11, 129. [CrossRef]

48. Wang, H.; Feng, G.; Xu, B.; Yu, Y.; Li, Z.; Du, Y.; Zhu, J. Deriving spatio-temporal development of ground subsidence due to subway construction and operation in delta regions with PS-InSAR data: A case study in Guangzhou, China. Remote Sens. 2017, 9, 1004. [CrossRef]

49. Fornaro, G.; Lombardini, F.; Pauciullo, A.; Reale, D.; Viviani, F. Tomographic Processing of Interferometric SAR Data: Developments, applications, and future research perspectives. IEEE Signal Process. Mag. 2014, 31, 41-50. [CrossRef]

50. Budillon, A.; Crosetto, M.; Johnsy, A.C.; Monserrat, O.; Krishnakumar, V.; Schirinzi, G. Comparison of Persistent Scatterer Interferometry and SAR Tomography Using Sentinel-1 in Urban Environment. Remote Sens. 2018, 10, 1986. [CrossRef]

51. Crosetto, M.; Budillon, A.; Monserrat, O. Urban Deformation Monitoring using Persistent Scatterer Interferometry and SAR tomography; MDPI: Basel, Switzerland, 2019.

52. Shi, Y.; Wang, Y.; Zhu, X.X.; Bamler, R. Non-Local SAR Tomography for Large-Scale Urban Mapping. In Proceedings of the IGARSS 2019-2019 IEEE International Geoscience and Remote Sensing Symposium, Yokohama, Japan, 28 July-2 August 2019; pp. 5197-5200.

53. Li, Y.; Martinis, S.; Wieland, M.; Schlaffer, S.; Natsuaki, R. Urban Flood Mapping Using SAR Intensity and Interferometric Coherence via Bayesian Network Fusion. Remote Sens. 2019, 11, 2231. [CrossRef]

54. Kuffer, M.; Pfeffer, K.; Sliuzas, R. Slums from space-15 years of slum mapping using remote sensing. Remote Sens. 2016, 8, 455. [CrossRef]

55. Kuffer, M.; Pfeffer, K.; Sliuzas, R.; Baud, I. Extraction of slum areas from VHR imagery using GLCM variance. IEEE J. Sel. Top. Appl. Earth Obs. Remote Sens. 2016, 9, 1830-1840. [CrossRef] 
56. Jensen, J.R.; Cowen, D.C. Remote sensing of urban/suburban infrastructure and socio-economic attributes. Photogramm. Eng. Remote Sens. 1999, 65, 611-622.

57. Lo, C.P.; Faber, B.J. Integration of Landsat Thematic Mapper and census data for quality of life assessment. Remote Sens. Environ. 1997, 62, 143-157. [CrossRef]

58. Martinuzzi, S.; Ramos-González, O.M.; Muñoz-Erickson, T.A.; Locke, D.H.; Lugo, A.E.; Radeloff, V.C. Vegetation cover in relation to socioeconomic factors in a tropical city assessed from sub-meter resolution imagery. Ecol. Appl. 2018, 28, 681-693. [CrossRef] [PubMed]

59. Haas, J.; Ban, Y. Sentinel-1A SAR and sentinel-2A MSI data fusion for urban ecosystem service mapping. Remote Sens. Appl. Soc. Environ. 2017, 8, 41-53. [CrossRef]

60. Yang, Y.; Wu, T.; Wang, S.; Li, J.; Muhanmmad, F. The NDVI-CV Method for Mapping Evergreen Trees in Complex Urban Areas Using Reconstructed Landsat 8 Time-Series Data. Forests 2019, 10, 139. [CrossRef]

61. Lin, D.; Gold, H.T.; Schreiber, D.; Leichman, L.P.; Sherman, S.E.; Becker, D.J. Impact of socioeconomic status on survival for patients with anal cancer. Cancer 2018, 124, 1791-1797. [CrossRef]

62. Rosengren, A.; Smyth, A.; Rangarajan, S.; Ramasundarahettige, C.; Bangdiwala, S.I.; AlHabib, K.F.; Avezum, A.; Bengtsson Boström, K.; Chifamba, J.; Gulec, S.; et al. Socioeconomic status and risk of cardiovascular disease in 20 low-income, middle-income, and high-income countries: The Prospective Urban Rural Epidemiologic (PURE) study. Lancet Glob. Health 2019, 7, e748-e760. [CrossRef]

63. Kim, S.w.; Kim, E.J.; Wagaman, A.; Fong, V.L. A longitudinal mixed methods study of parents' socioeconomic status and children's educational attainment in Dalian City, China. Int. J. Educ. Dev. 2017, 52, 111-121. [CrossRef]

64. McKenzie, D.J. Measuring inequality with asset indicators. J. Popul. Econ. 2005, 18, 229-260. [CrossRef]

65. Renard, F.; Devleesschauwer, B.; Speybroeck, N.; Deboosere, P. Monitoring health inequalities when the socio-economic composition changes: Are the slope and relative indices of inequality appropriate? Results of a simulation study. BMC Public Health 2019, 19, 662. [CrossRef]

66. Hoffmann, R.; Kröger, H.; Pakpahan, E. Pathways between socioeconomic status and health: Does health selection or social causation dominate in Europe? Adv. Life Course Res. 2018, 36, 23-36. [CrossRef]

67. Tighe, L.; Webster, N.J. The Influence of Socioeconomic Status on health and Well-Being: Comparing Diverse Trajectories. Innov. Aging 2017, 1, 983-984. [CrossRef]

68. Kivimäki, M.; Batty, G.D.; Pentti, J.; Shipley, M.J.; Sipilä, P.N.; Nyberg, S.T.; Suominen, S.B.; Oksanen, T.; Stenholm, S.; Virtanen, M. Association between socioeconomic status and the development of mental and physical health conditions in adulthood: A multi-cohort study. Lancet Public Health 2020, 5, e140-e149. [CrossRef]

69. Lampert, T.; Kroll, L.E.; Kuntz, B.; Hoebel, J. Gesundheitliche Ungleichheit in Deutschland und im Internationalen Vergleich: Zeitliche Entwicklungen und Trends; Robert-Koch-Institut: Berlin, Germany, 2018.

70. Guterres, A. Sustainable Cities, Human Mobility and Internationalmigration; United Nations Economic and Social Council: New York, NY, USA, 2018.

71. United Nations Human Settlements Programme. Belmopan Urban Development. Towards a Sustainable Garden City; Earthscan: London, UK, 2017.

72. Statistical Institute of Belize. Annual Report 2018-19; Statistical Institute of Belize: Belmopan, Belize, 2019.

73. Kaza, S.; Yao, L.; Bhada-Tata, P.; Van Woerden, F. What a Waste 2.0: A Global Snapshot of Solid Waste Management to 2050; The World Bank: Washington, DC, USA, 2018.

74. Airbus Defence and Space. Pléiades Neo. Trusted Intelligence. Available online: https://www.intelligenceairbusds.com/en/8671-pleiades-neo-trusted-intelligence (accessed on 11 November 2019).

75. Maxar. WorldView Legion. Our Next-generation Constellation. Available online: https://www.maxar.com/ splash/worldview-legion (accessed on 12 February 2020).

76. Kearns, K.C. Belmopan: Perspective on a new capital. Geogr. Rev. 1973, 63, 147-169. [CrossRef]

77. Friesner, J. Hurricanes and the Forests of Belize; Forest Planning and Management Project; Ministry of Natural Resources: Belmopan, Belize, 1993.

78. Statistical Institute of Belize. Annual Report 2017-18; Statistical Institute of Belize: Belmopan, Belize, 2018.

79. DigitalGlobe. WorldView-1. Available online: https://www.euspaceimaging.com/wp-content/uploads/2018/ 08/WorldView1-DS-WV1_V02.pdf (accessed on 3 December 2019).

80. Planet Team. Planet Application Program Interface: In Space for Life on Earth; San Francisco. 2017. Available online: https://api.planet.com (accessed on 2 February 2019). 
81. Planet. Planet Imagery Product Specification: Planetscope \& Rapideye. Available online: https://www.planet.com/products/satellite-imagery/files/1610.06_Spec\%20Sheet_Combined_Imagery_ Product_Letter_ENGv1.pdf (accessed on 1 September 2019).

82. Pham, P. KoBo Toolbox. In Proceedings of the Measure GIS Working Group Meeting, Rosslyn, VA, USA, 26 June 2012.

83. Haklay, M.; Weber, P. Openstreetmap: User-generated street maps. IEEE Pervasive Comput. 2008, 7, 12-18. [CrossRef]

84. Hexagon. Erdas Imagine 2018. Available online: https://download.hexagongeospatial.com/en/downloads/ imagine/erdas-imagine-2018 (accessed on 11 January 2019).

85. Legner, S. JOSM-Java OpenStreetMap Editor. In Proceedings of the FOSSGIS 2012, Dessau, Germany, 20-22 March 2012.

86. Hashim, H.; Abd Latif, Z.; Adnan, N.A. Urban Vegetation Classifiction With NDVI Threshold Value Method with Very High Resolution (VHR) Pleiades Imagery. Int. Arch. Photogramm. Remote Sens. Spat. Inf. Sci. 2019, XLII-4/W16, 237-240. [CrossRef]

87. Vetter-Gindele, J.; Braun, A.; Warth, G.; Bui, T.T.; Bachofer, F.; Eltrop, L. Assessment of Household Solid Waste Generation and Composition by Building Type in Da Nang, Vietnam. Resources 2019, 8, 171. [CrossRef]

88. Point2homes. 2-Storey House. Available online: https://www.point2homes.com (accessed on 13 December 2019).

89. Lang, S.; Blaschke, T. Landschaftsanalyse mit GIS; Ulmer: Stuttgart, Germany, 2007; p. 405.

90. Breiman, L. Random Forests. Mach. Learn. 2001, 45, 5-32. [CrossRef]

91. Winkler, J.; Stolzenberg, H. Der Sozialschichtindex im Bundes-Gesundheitssurvey. Gesundheitswesen 1998, 61, 178-183.

92. Singh, T.; Sharma, S.; Nagesh, S. Socio-economic status scales updated for 2017. Int. J. Res. Med. Sci. 2017, 5, 3264-3267. [CrossRef]

93. Biewen, M.; Juhasz, A. Direct Estimation of Equivalence Scales and More Evidence on Independence of Base. Oxf. Bull. Econ. Stat. 2017, 79, 875-905. [CrossRef]

94. Kau, J.B.; Sirmans, C.F. Urban land value functions and the price elasticity of demand for housing. J. Urban Econ. 1979, 6, 112-121. [CrossRef]

95. Pascascio, K.; (Belmopan City Council, Belmopan, Belize). Personal communication, 2019.

96. Zhu, Z.; Zhou, Y.; Seto, K.C.; Stokes, E.C.; Deng, C.; Pickett, S.T.A.; Taubenböck, H. Understanding an urbanizing planet: Strategic directions for remote sensing. Remote Sens. Environ. 2019, 228, 164-182. [CrossRef]

97. Nex, F.; Remondino, F. UAV for 3D mapping applications: A review. Appl. Geomat. 2014, 6, 1-15. [CrossRef] 